\title{
Importance of Reelin C-Terminal Region in the Development and Maintenance of the Postnatal Cerebral Cortex and Its Regulation by Specific Proteolysis
}

\author{
Takao Kohno, ${ }^{1 *}$ Takao Honda, ${ }^{2 *}$ Ken-ichiro Kubo, ${ }^{2 *}$ Yoshimi Nakano, ${ }^{1}$ Ayaka Tsuchiya, ${ }^{1}$ Tatsuro Murakami, ${ }^{1}$ \\ Hideyuki Banno, ${ }^{1}$ Kazunori Nakajima, ${ }^{2} \dagger$ and Mitsuharu Hattori ${ }^{1} \uparrow$ \\ ${ }^{1}$ Department of Biomedical Science, Graduate School of Pharmaceutical Sciences, Nagoya City University, Aichi 467-8603, Japan, and ${ }^{2}$ Department of \\ Anatomy, Keio University School of Medicine, Tokyo 160-8582, Japan
}

During brain development, Reelin exerts a variety of effects in a context-dependent manner, whereas its underlying molecular mechanisms remain poorly understood. We previously showed that the C-terminal region (CTR) of Reelin is required for efficient induction of phosphorylation of Dab1, an essential adaptor protein for canonical Reelin signaling. However, the physiological significance of the Reelin CTR in vivo remains unexplored. To dissect out Reelin functions, we made a knock-in (KI) mouse in which the Reelin CTR is deleted. The amount of Dab1, an indication of canonical Reelin signaling strength, is increased in the KI mouse, indicating that the CTR is necessary for efficient induction of Dab1 phosphorylation in vivo. Formation of layer structures during embryonic development is normal in the KI mouse. Intriguingly, the marginal zone (MZ) of the cerebral cortex becomes narrower at postnatal stages because upper-layer neurons invade the MZ and their apical dendrites are misoriented and poorly branched. Furthermore, Reelin undergoes proteolytic cleavage by proprotein convertases at a site located 6 residues from the $C$ terminus, and it was suggested that this cleavage abrogates the Reelin binding to the neuronal cell membrane. Results from ectopic expression of mutant Reelin proteins in utero suggest that the dendrite development and maintenance of the MZ require Reelin protein with an intact CTR. These results provide a novel model regarding Reelin functions involving its CTR, which is not required for neuronal migration during embryonic stages but is required for the development and maintenance of the MZ in the postnatal cerebral cortex.

Key words: Dab1; dendrite; knock-in mouse; neuronal migration; proteolysis; Reelin

\section{Introduction}

Reelin is a large secreted glycoprotein (D'Arcangelo et al., 1995; Ogawa et al., 1995) essential for the correct formation of multiple regions of the nervous system (Tissir and Goffinet, 2003). Defects

Received Oct. 3, 2014; revised Feb. 17, 2015; accepted Feb. 19, 2015.

Author contributions: T.K., T.H., K.N., and M.H. designed research;T.K., T.H., K.-i.K.,Y.N., A.T., T.M., H.B., and M.H. performed research; T.K., T.H., K.-i.K., K.N., and M.H. analyzed data; T.K., T.H., K.-i.K., K.N., and M.H. wrote the paper.

This work was supported by Grants-in-aid KAKENHI 22890155 and 24790081 to T.K., 21700383 and 24700357 to T.H., 25116522 and 26430075 to K.-i.K., 22390016,23123519 , and 24659036 to M.H., 22111004 and 25640039 to K.N., the Strategic Research Program for Brain Sciences of Ministry of Education, Culture, Sports, Science and Technology to K.N., Keio Gijuku Academic Development Funds to K.-i.K. and K.N., Program for the Advancement of Keio Next Generation Research Projects to K.-i.K., Terumo Life Science Foundation to K.N., Life Science Foundation of Japan to K.N., and the Takeda Science Foundation to M.H. We thank Profs. J. Takagi (Osaka University), K. Mikoshiba (RIKEN), and D. Feldheim (University of California, Santa Cruz) for valuable comments; Prof. J. Aoki (Tohoku University) for help in establishing monoclonal antibodies; Dr. S. Kanatani for help constructing tdTomato/pCAG (Kanatani et al., manuscript in preparation); and Drs. T. Curran (Reelin), K. Nakayama (furin), Q. Lu (Dcx4kb-EGFP), S. Miyagawa (pCXN-Cre), and J. Miyazaki (pCAGGS) for providing plasmids.

The authors declare no competing financial interests.

*T.K., T.H., and K.-i.K. contributed equally to this work.

†K.N. and M.H. contributed equally to this work.

Correspondence should be addressed to either of the following: Dr. Kazunori Nakajima, Department of Anatomy, Keio University School of Medicine, 35 Shinanomachi, Shinjuku-ku, Tokyo 160-8582, Japan. E-mail: kazunori@keio.jp.; or Dr. Mitsuharu Hattori, Department of Biomedical Science, Graduate School of Pharmaceutical Sciences, Nagoya City University, 3-1 Tanabe-dori, Mizuho-ku, Nagoya, Aichi 467-8603, Japan. E-mail: mhattori@phar.nagoya-cu.ac.jp.

DOI:10.1523/JNEUROSCI.4119-14.2015

Copyright $\odot 2015$ the authors $\quad 0270-6474 / 15 / 354776-12 \$ 15.00 / 0$ in Reelin function have been proposed to play a role in the pathogenesis of several neuropsychiatric diseases (Verbrugghe et al., 2012; Folsom and Fatemi, 2013). However, the mechanisms of action of Reelin at the biochemical and cell biological levels remain unresolved.

In the developing neocortex, Reelin is predominantly expressed in Cajal-Retzius cells in the marginal zone (MZ) (D'Arcangelo et al., 1995; Ogawa et al., 1995). Reelin binds to “canonical” Reelin receptors (apolipoprotein E receptor 2 [ApoER2] and very low density lipoprotein receptor [VLDLR]) (D’Arcangelo et al., 1999; Hiesberger et al., 1999; Trommsdorff et al., 1999) and induces phosphorylation of the intracellular protein Dab1 (Howell et al., 1999; Howell et al., 2000). Phosphorylated Dab1 is quickly degraded (Arnaud et al., 2003); thus, Dab1 protein accumulates in Reelindeficient reeler mice (Rice et al., 1998; Howell et al., 1999, 2000). Reelin-Dab1 signaling is necessary for the terminal translocation of migrating projection neurons by regulating cell orientation via Rap1/N-cadherin (Franco et al., 2011; Jossin and Cooper, 2011) and neuronal adhesion to the extracellular matrix via Rap1/integrin $\alpha 5 \beta 1$ (Sekine et al., 2012).

Reelin consists of an F-spondin-like region, eight Reelin repeats (RRs), and a carboxy-terminal region (CTR) (D'Arcangelo et al., 1995; Ichihara et al., 2001). The central part of the RR region binds to the canonical Reelin receptors (Jossin et al., 2004; 
Yasui et al., 2007). The presence of the CTR is regulated by alternative splicing, with CTR-bearing Reelin being the major isoform (Lambert de Rouvroit et al., 1999). Early studies proposed that the CTR was important for Reelin secretion (D'Arcangelo et al., 1997; de Bergeyck et al., 1997). However, we have shown that the CTR sequence is replaceable with an unrelated sequence for secretion and is necessary for efficient induction of Dab1 phosphorylation in vitro (Nakano et al., 2007), presumably by affecting the tertiary structure of RR8 (Kohno et al., 2009b). The role of the Reelin CTR has not been investigated in vivo.

Reelin is regulated by two kinds of specific proteolysis. Cleavage within RR3 abolishes Reelin's ability to induce Dab1 phosphorylation (Kohno et al., 2009a; Koie et al., 2014). Cleavage between RR6 and RR7 may be involved in regulating synaptic plasticity (Trotter et al., 2014). Other than these, the mechanisms for regulating Reelin function are largely uncharacterized.

Here we generated a knock-in (KI) mouse in which the Reelin CTR was deleted to clarify its role in vivo. We found that Reelin is proteolytically cleaved within the CTR by proprotein convertase (PC) family proteases and that such cleavage reduces Reelin's ability to induce a dendrite-rich MZ-like structure. Our data demonstrate a novel role and regulatory mechanism for Reelin in postnatal brain development, which clarifies the underlying mechanisms by which Reelin plays distinct location-dependent functional roles in neural development.

\section{Materials and Methods}

Animals. All of the experimental protocols used in this study were approved by the Animal Care and Use Committees of Nagoya City University and Keio University and were performed according to the Guidelines for the Care and Use Laboratory Animals of the National Institutes of Health of Japan and the Institutional Guidelines on Animal Experimentation at Keio University. ICR mice were obtained from Charles River or from Japan SLC. Reeler mice (B6C3Fe-a/a- $r l$ ) were purchased from The Jackson Laboratory. GAD67-GFP KI mice (Tamamaki et al., 2003) were kindly provided by Prof. Y. Yanagawa (Gunma University, Japan). The $\mathrm{KI}$ mice in which the Reelin CTR was deleted ( $\Delta \mathrm{C}$-KI mice) were generated as follows. Mutations were introduced into the mouse reelin gene by homologous recombination in mouse ES cells (C57BL/6). ES clones were screened for homologous recombination by PCR analysis using primer: forward, CGTTCTAAGTTGCAATGAGATAACTG; and neo-cassette specific primer: reverse, CTTCCTCGTGCTTTACGGTATC. Genomic DNA from the PCR-positive clones was digested with EcoR I or HindIII and screened for correct homologous recombination by Southern blotting. The chimeric mouse line was generated by injecting the selected ES cells into the blastocysts of BALB/c mice. The contribution of the selected ES cells to the germline of chimeric mice was assessed by breeding with C57BL/ 6 females and screening for black offspring. The modified region of the Reelin gene was PCR amplified, confirming the presence of the intended modifications, using the primers: AGAATAAATCATACGTTCATTGGTG and CGTGAAGACATTTACTTATGTGCAG. The targeted Reelin gene had a loxP-flanked selection marker (a neomycin resistance gene with PGK promoter and polyA signal) inserted in intron 64 of the mouse Reelin gene. The selection marker was removed by crossing with CAG-Cre mice. After backcrosses for at least eight generations to C57BL/6N (Japan SLC), heterozygotes were intercrossed to obtain wild-type, heterozygote, and $\Delta \mathrm{C}$-KI mice.

For genotyping, the tip of the tail was excised, placed in a solution containing $25 \mathrm{~mm} \mathrm{NaOH}$ and $1 \mathrm{~mm}$ EDTA, and incubated at $98^{\circ} \mathrm{C}$ for $1 \mathrm{~h}$. The solution was then neutralized with the equal amount of $40 \mathrm{~mm}$ Tris, $\mathrm{pH}$ 5.5. An aliquot was used as a PCR template. PCR was performed with primers AGAATAAATCATACGTTCATTG and CGTGAAGACATTTACTTATGTG, which produced products of $380 \mathrm{bp}$ (WT band) and 320 bp (mutant band).

Antibodies. The following antibodies were used for Western blotting (WB), immunoprecipitation, or immunohistochemistry (IHC): mouse
anti-Reelin G10 (MAB5364, Millipore, WB 1:2000), mouse anti-Reelin E5 (sc-25346, Santa Cruz Biotechnology, WB 1:1000), goat anti-Reelin (AF3820, R\&D Systems, IHC 1:2000), mouse anti-Reelin CR-50 (D223-3, MBL, immunoprecipitation 1:300), mouse anti-FLAG M2 (F3165, Sigma-Aldrich, WB 1:1000), rabbit anti-DDDDK-tag (PM020, MBL, WB 1:500), rabbit anti-green fluorescent protein (GFP) (598, MBL, WB 1:3000), mouse anti-phosphotyrosine 4G10 (05-321, Millipore, WB 1:1000); rabbit anti-placental alkaline phosphatase (AP) (GTX72989, Gene Tex, WB 1:1000), mouse anti- $\alpha$-tubulin DM1A (T6199, Sigma-Aldrich, WB 1:6000), rabbit anti-Cux1 M-222 (sc-13024, Santa Cruz Biotechnology, IHC 1:500), rabbit anti-Tbr1 (ab31940, Abcam, IHC 1:500), rat anti-Ctip2 (ab18465, Abcam, IHC 1:500), and mouse anti-NeuN (MAB377, Millipore, IHC 1:500). Anti-Dab1 rabbit polyclonal antibody was previously described (Uchida et al., 2009). AntiCTR antibodies, 12C10 and 1D4, were obtained as follows. A peptide (CGLRHFYNRRRRSLRRYP) was coupled to keyhole limpet hemocyanin (Wako). Peptide-keyhole limpet hemocyanin conjugates were used to immunize GANP mice (Sakaguchi et al., 2005) or homozygous reeler mice. Monoclonal antibodies were generated by lymphocyte fusion (Sado et al., 2006). Hybridomas were screened by ELISA and WB. The antibody in the hybridoma supernatants was purified using a Hitrap Protein-G Sepharose HP column (GE Healthcare) on an ÄKTAexplorer 10S (GE Healthcare). Protein concentrations were measured using the Quick Start Bradford $1 \times$ Dye Reagent (Bio-Rad).

Vector construction. Expression vectors for ReelinFLAG $+\mathrm{C}$ and Reelin $\Delta$ C-FLAG were described previously (Nakano et al., 2007). The Reelin cDNA construct, pCrl (D'Arcangelo et al., 1997), was used to express mouse wild-type Reelin (ReelinWT) and as a template for PCR amplification. ReelinC-FLAG, ReelinC-Venus, and Reelin $\Delta 6$ were constructed in pcDNA3.1Zeo + (Invitrogen). AP-RR78C was constructed in pAPtag5 (Flanagan et al., 2000). For site-directed mutagenesis, point mutations were introduced into the CTR coding sequence by PCR. The expression vector for furin was kindly provided by Prof. K. Nakayama (Kyoto University). For in utero electroporation studies, the coding region of ReelinC-FLAG, Reelin $\Delta 6$, or Reelin $\Delta$ C-FLAG was subcloned into a pCAGGS vector (Niwa et al., 1991). pCAGGS-EGFP was described previously (Kubo et al., 2010). pCAGGS-RG was constructed by Dr. S. Sasaki (manuscript in preparation). To construct pDCX-Cre, the doublecortin (DCX) promoter, Cre cDNA, and rabbit $\beta$-globin poly A adenylation signal were obtained from Dcx4kb-EGFP (Wang et al., 2007), kindly provided by Dr. Q. Lu (Beckman Research Institute of the City of Hope); pCXN-Cre (Koresawa et al., 2000), kindly provided by Dr. S. Miyagawa (Osaka University); and pCAGGS, respectively, and the fragments were introduced into pBluescript II KS (-). To construct tdTomato/pCAG, the BamH I/NotI fragment of the ptdTomato vector (Clontech) was introduced into the CAG-MCS2 vector (Kawauchi et al., 2005).

Cell culture and transfection. HEK293T and COS-7 cells were cultured as described previously (Kohno et al., 2009b). LoVo cells (JCRB9083) were cultured in Ham's F12 medium containing 10\% FCS. Transfection was performed with Lipofectamine 2000 (Invitrogen) according to the manufacturer's instructions. Culture medium was replaced with OptiMEM (Invitrogen) to collect recombinant Reelin. To inhibit the activity of the PC family proteases, cells or neurons were cultured in the presence of $50 \mu \mathrm{M}$ decanoly-RVKR-cmk (furin inhibitor I, Millipore), $50 \mu \mathrm{M}$ hexaD-arginine (furin inhibitor II, Millipore), or $0.25 \%$ DMSO as vehicle for $48-72 \mathrm{~h}$.

Quantitation of the amount of Dab1. Cortical lobes were excised from mice at postnatal day $3(\mathrm{P} 3)$ and homogenized in lysis buffer $(50 \mathrm{~mm}$ Tris-HCl, pH 8.0, 150 mм NaCl, 5 mм EDTA, 1\% Triton X-100, 0.1\% sodium deoxycholate, $10 \mathrm{mM} \mathrm{Na}_{3} \mathrm{VO}_{4}$ ). The total protein concentration was determined using the BCA Protein Assay Kit (Thermo Fisher Scientific). Equal aliquots of protein $(10 \mu \mathrm{g})$ were analyzed by SDS-PAGE, followed by WB using anti-Dab1 and anti- $\alpha$-tubulin antibodies.

WB. WB was performed as described previously (Nakano et al., 2007). Immunoprecipitation from mouse brain extracts was performed as described previously (Kohno et al., 2009b).

Primary neuron culture and Dab1 phosphorylation assay. Primary cortical neurons were prepared from mice as described previously (Kohno et 
al., 2009b). Induced phosphorylation of Dab1 was performed as described previously (Kohno et al., 2009b; Koie et al., 2014).

Nissl staining. Cryostat sections were immersed in $0.1 \%$ cresyl violet for $10 \mathrm{~min}$, dehydrated in increasing concentrations of ethanol, and mounted with Softmount (Wako).

IHC. Embryonic brains were immediately immersed in 4\% PFA in PBS for $1-16 \mathrm{~h}$ at $4^{\circ} \mathrm{C}$. Neonates were transcardially perfused with $4 \%$ PFA in PBS. Fixed brains were cryoprotected by immersion in 30\% sucrose in PBS, embedded in OCT Compound (Sakura Finetek), and quickly frozen in liquid nitrogen. Next, the frozen brains were coronally sectioned at 14 $\mu \mathrm{m}$ using a cryostat (CM 1850; Leica Microsystems). The sections were incubated with $2 \%$ BSA in PBS containing $0.05 \%$ Tween 20 at room temperature for $30 \mathrm{~min}$, and incubated with the primary antibodies at $4^{\circ} \mathrm{C}$ overnight. The sections were then washed with PBS containing $0.05 \%$ Tween 20 and incubated with Alexa488- and Alexa594conjugated secondary antibodies (1:400, Invitrogen) at room temperature for $1 \mathrm{~h}$. For nuclear staining, Hoechst 33342 ( $2 \mu \mathrm{g} / \mathrm{ml}$; Invitrogen $)$ was used. Fluorescence images were captured using Biorevo BZ-9000 (Keyence).

AP staining. Primary cultured neurons were incubated with AP fusion proteins with the indicated antibody $(50 \mu \mathrm{g} / \mathrm{ml})$ for $2 \mathrm{~h}$, and AP staining was performed as described previously (Flanagan et al., 2000).

In utero electroporation. To introduce vector DNA into cerebral cortical neurons, in utero electroporation was performed on E14.5 mice as described previously (Tabata and Nakajima, 2001). For cohort neuron labeling, a DNA solution containing $2.5 \mathrm{mg} / \mathrm{ml}$ pCAGGS-EGFP was used. For sparse neuron labeling, a DNA solution containing $2.5 \mathrm{mg} / \mathrm{ml}$ pCAGGS-RG and $5 \mu \mathrm{g} / \mathrm{ml}$ pDCX-Cre was used. The DNA solutions were injected into the lateral ventricle using a glass capillary and $50 \mathrm{~ms} 34 \mathrm{~V}$ electronic pulses were applied 4 times at intervals of $950 \mathrm{~ms}$ using an electroporator (CUY21; Nepa Gene) with a forceps-type electrode (CUY650P5; Nepa Gene). At P7, mice were anesthetized and transcardially fixed with $4 \%$ PFA in PBS. Single focal plane images were taken with a FV1000 laser scanning confocal microscope (LSM; Olympus). The distance from the ventricular surface to the cell bodies of DsRed2- and GFP-labeled cells (D1), and the distance from the ventricular surface to the top of the cortex (D2) were measured using ImageJ software (http://imagej.nih.gov/ij/); bin positions were calculated by dividing D1 by $\mathrm{D} 2$ and multiplying by 20 . To quantify the ratio of the cortical plate-MZ border crossing cells, single focal plane images were acquired and GFP-positive apical dendrites were traced. To quantify the total length and branching points of apical dendrites, the GFP signal in the entire thickness of the sections was obtained by $z$-scan using the LSM; the stacked images were flattened, the apical dendrite lengths were measured using ImageJ, and the branching points were counted.

Analysis of neuronal aggregates. To induce neuronal aggregates, a DNA solution containing $1 \mathrm{mg} / \mathrm{ml}$ tdTomato/pCAG and $5 \mathrm{mg} / \mathrm{ml} \mathrm{ReelinC-}$ FLAG, Reelin $\Delta$ C-FLAG, or Reelin $\Delta 6$ was transfected at E14.5 and analyzed $7 \mathrm{~d}$ later. The nuclei in brain sections were labeled with DAPI (Invitrogen). To analyze cell distribution in induced neuronal aggregates, $100 \mu \mathrm{m}$ sections were selected for analysis where the aggregates were isolated (not fused with other aggregates), and the aggregate diameters were larger than those in adjacent serial sections. Single confocal images were acquired using a confocal microscope (FV1000, Olympus). The margins of the neuronal aggregates and central cell-sparse regions were delineated with lines, and the areas within the lines were measured using ImageJ. Relative areas of central cell-body-sparse regions (centers) were quantitatively evaluated by dividing the areas of centers by the areas of aggregates in seven aggregates from seven different brains.

To quantify cell density, cellular nuclei were marked with dots and counted using ImageJ. The peripheral areas were acquired by subtracting the areas of centers from the areas of aggregates. Next, cell densities were calculated by dividing the number of dots by the peripheral areas in seven aggregates from seven different brains.

To quantify the angles of neuronal processes in the aggregates, the centers of the aggregates were calculated as follows. The nuclei were marked with dots, and the barycentric coordinates of the dots were calculated by averaging the $x$ - and $y$-coordinates of all dots measured using ImageJ. The barycentric coordinates calculated were assumed to be the centers of the aggregates. The angle formed between the line that connected the center of the aggregate and the center of each cellular nucleus and a second line that connected the origin of the apical dendrite and the center of each cellular nucleus was measured using ImageJ. The number of tdTomato-positive cells counted in aggregates transfected with ReelinC-FLAG, Reelin $\Delta 6$, and Reelin $\Delta$ C-FLAG were 59, 62, and 83, respectively, in seven aggregates from seven different brains.

Statistical analysis. All quantitative data were expressed as the mean \pm SEM. For direct comparisons, the data were analyzed using the MannWhitney $U$ test, one sample $t$ test, or unpaired $t$ test. For multiple comparisons, ANOVA was performed, followed by Tukey's test. $p$ values $<0.05$ were considered to denote significance.

\section{Results}

\section{Reelin-Dab1 signaling is attenuated in mice lacking Reelin CTR}

We generated a KI mouse in which the Reelin CTR was replaced with a FLAG epitope (DYKDDDDK) by homologous recombination, followed by removal of a neo-cassette by Cre recombinase ( $\Delta \mathrm{C}$-KI mouse; Fig. $1 A-C$ ). The FLAG-tag was inserted because Reelin secretion efficiency without the CTR is lower than with the CTR or FLAG-tag in cultured cell lines (Fig. 1D) (Nakano et al., 2007). The $\Delta \mathrm{C}$-KI mouse is viable and does not exhibit ataxic behavior, unlike the reeler mouse. The expression pattern of Reelin and density of Cajal-Retzius cells in MZ were not affected in $\Delta$ C-KI mice (Fig. $1 E$ ), although accumulation of Reelin protein was observed in some Cajal-Retzius cells (Fig. 1E, arrows), as was observed in cultured cell lines (Nakano et al., 2007). The amount of Reelin in the cerebral cortex was increased in $\Delta \mathrm{C}$-KI mice compared with wild-type mice (Fig. $1 F$ ). Secretion of Reelin, assessed by using primary cultured neurons, was almost comparable between wild-type and $\Delta \mathrm{C}$-KI mice, whereas Reelin tended to accumulate within the $\Delta \mathrm{C}$-KI neurons (Fig. $1 G$ ). The amount of Dab1 protein in the homogenate prepared form whole cerebral cortex, an indication of overall Reelin activity, was significantly increased in $\Delta \mathrm{C}$-KI mice compared with wild-type mice (Fig. $1 H$, lane 3), suggesting that the Reelin-Dab1 pathway is partially impaired in $\Delta \mathrm{C}$-KI mice. These results suggested that Reelin CTR has important functions in vivo.

\section{The layer structure of cerebral cortex is largely normal but the $\mathrm{MZ}$ is narrower and hippocampal structure is disturbed in $\Delta \mathrm{C}-\mathrm{KI}$ mice}

The brains of $\Delta \mathrm{C}$-KI mice appeared grossly normal (Fig. 2A, $B$ ). However, we noted that the MZ or layer I of the cerebral cortex became narrower in postnatal $\Delta \mathrm{C}$-KI mice compared with normal littermates (Fig. 2B, arrowheads). The narrowness varied among cortical regions. For example, the $\mathrm{MZ}$ was narrower in the presumptive somatosensory cortex (Fig. $2 A^{\prime \prime}, B^{\prime \prime}$ ) than in the motor cortex (Fig. $2 A^{\prime}, B^{\prime}$ ). In the hippocampus of $\Delta \mathrm{C}$-KI mice, the CA1 pyramidal cell layer was split into two layers (Fig. $2 B$, arrows, $C$ ), and the dentate granule cell layer was less packed (Fig. $2 B$, surrounded by broken line) compared with normal littermates. The narrowness of the MZ in $\triangle \mathrm{C}$-KI mice was not observed during the embryonic stages (Fig. 2D, top) and was apparent at postnatal day 5 (P5) (Fig. 2D, bottom). We then found that the structural defects in the cerebral cortex were first evident around P3. Staining of layer-specific markers of P3 cerebral cortical slices revealed that the distribution of Cux1-positive neurons extended into the MZ in $\Delta \mathrm{C}$-KI mice (Fig. 2 E, G). On the other hand, the localization of neurons in deeper layers (Tbr1- or Ctip2-positive) was largely normal (Fig. 2F, $H, I$ ). The MZ and densely packed NeuN-negative zone beneath the $\mathrm{MZ}$ (primitive cortical zone [PCZ]) (Sekine et al., 2011) were observed in the 
A
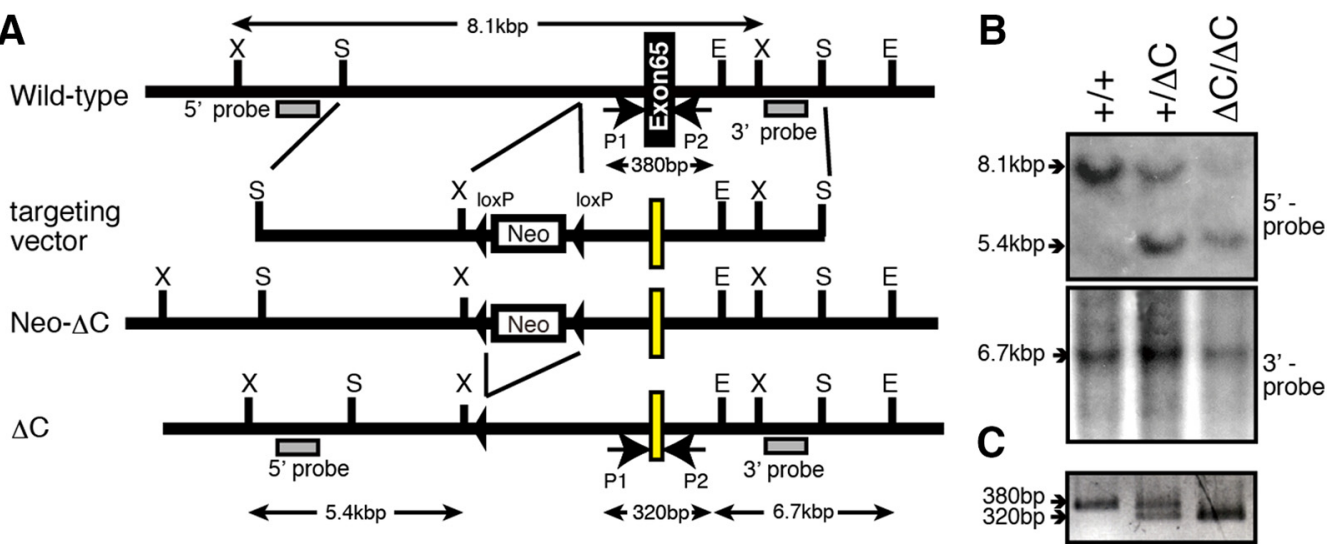

D

ReelinWT

Reelin $\triangle$ C-FLAG

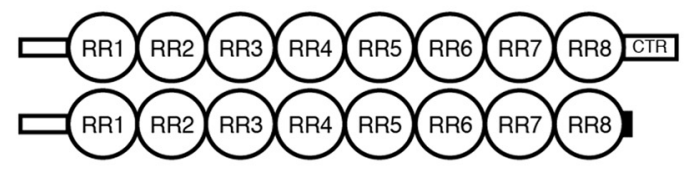

E

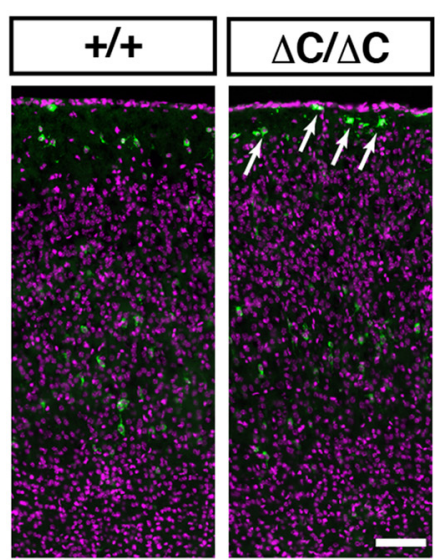

Reelin/Nuclei

G
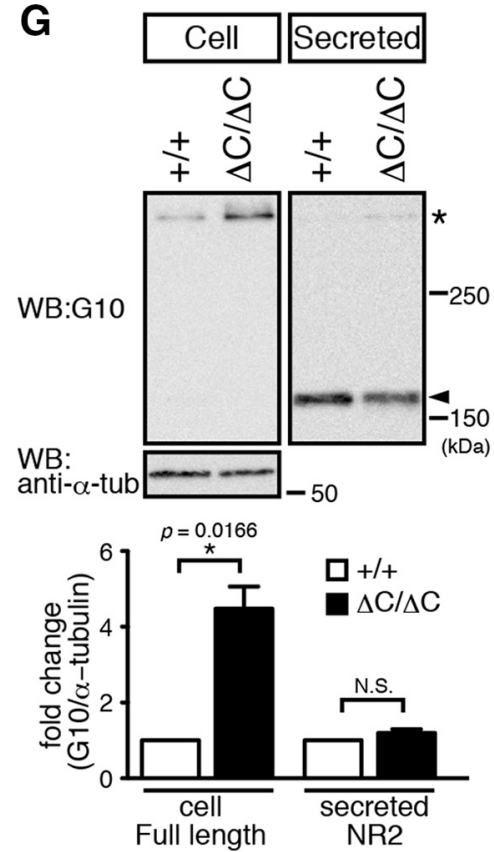

F

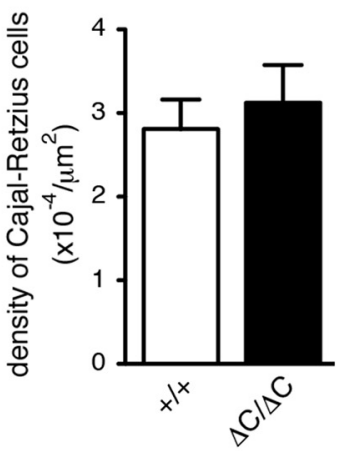

H Brain homogenate

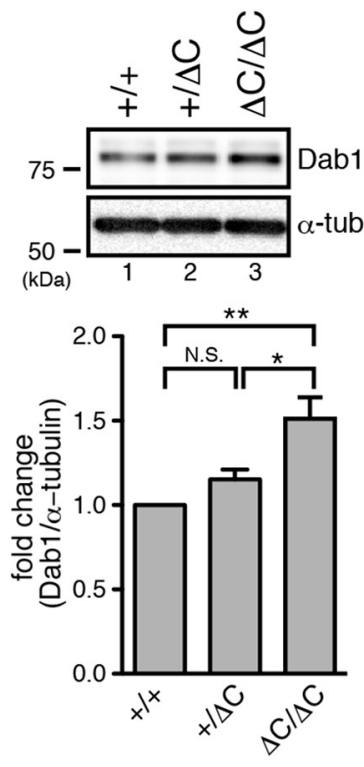

F Brain homogenate

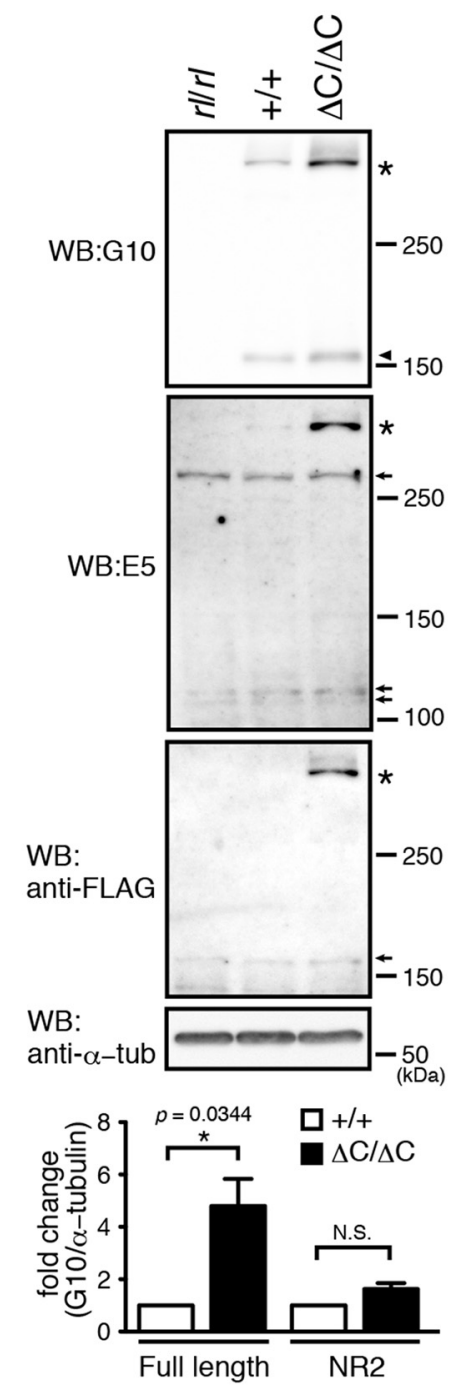

Figure 1. Generation of a KI mouse with deletion of the Reelin CTR. $A$, Schematic of the wild-type allele, targeting vector, Neo- $\Delta$ C allele, and $\Delta C$ allele. Neo- $\Delta C$ mice were bred with CAG-Cre transgenic mice to eliminate the neomycin-resistance cassette. the FLAG-epitope coding exon is highlighted in yellow. E, S, and Xindicate recognition sites for EcoRI, Spel, and Xbal, respectively. $\boldsymbol{B}$, The genotypes were confirmed by Southern blotting. Genomic DNA from the tail of the wild-type $(+/+)$, heterozygote $(+/ \Delta C)$, or $\Delta C-K I(\Delta C / \Delta C)$ mice was digested with Xbal or EcoR I and hybridized with 5' - or 3'-probes (shown in A), respectively. C, Genotype analysis using PCR. Using the P1 and P2 primers (shown in A), 380 and 320 bp fragments were (Figure legend continues.) 
wild-type cortex at P2, whereas both zones were disorganized with a blurred border in $\Delta \mathrm{C}$-KI mice (Fig. $2 J$ ). The distribution of GAD67-positive interneurons was normal in $\Delta \mathrm{C}-\mathrm{KI}$ mice (Fig. $2 \mathrm{~K}$ ). These results indicate that Reelin CTR is required for correct formation and/or maintenance of the MZ in the cerebral cortex.

\section{Dendritic orientation and branching are affected in mice lacking Reelin CTR}

Reelin is required for the orientation and branching of dendrites near the MZ (Sekine et al., 2011, 2012; Chai et al., 2014), which may play a role in the correct formation and/or maintenance of the MZ. We thus investigated the morphology of individual neurons near the $\mathrm{MZ}$ in $\Delta \mathrm{C}-\mathrm{KI}$ mice, to understand the importance of the CTR-dependent pathway. For this purpose, a GFPexpression vector was introduced by in utero electroporation at E14.5 and the brains were analyzed at P7. As shown in Figure 3A, GFP-expressing cells were more scattered in the superficial layers in $\Delta \mathrm{C}$-KI mice than in wild-type mice. To quantitatively analyze the neuronal morphology, pCAGGS-RG and pDCX-Cre were cointroduced at E14.5 and the brains were analyzed at P7 (Fig. $3 B$ ). With this technique, only neurons that had been transfected by both vectors are labeled with GFP. This "sparse-labeling" enabled us to observe the morphology and position of a single neuron (Sekine et al., 2012). We found that apical dendrites were often misoriented or poorly branched near or in the $\mathrm{MZ}$ of the $\Delta \mathrm{C}$-KI mice (Fig. $3 C$ ). The total apical dendrite length (Fig. $3 D, E$ ), the number of apical dendrite branching points (Fig. $3 F, G$ ), and the percentage of cells that have apical dendrites crossing the CP-MZ border (Fig. $3 H$ ) were significantly reduced in $\Delta \mathrm{C}$-KI mice compared with normal littermates. Interestingly, the GFP-labeled neurons did not form a packed layer in $\Delta \mathrm{C}$-KI mice, and a downward shift in relative bin position was observed (Fig. 3I). This may have been caused secondarily by the preexisting disordered structure or by abnormal migration of a subset of neurons. Together, these data indicate that Reelin CTR is required for proper orientation and branching of apical dendrites and positioning of neurons in the postnatal cerebral cortex.

\footnotetext{
$\leftarrow$

(Figure legend continued.) amplified from wild-type and $\Delta$ C alleles, respectively. $\boldsymbol{D}$, Schematic of wild-type Reelin (ReelinWT) and Reelin $\Delta$ C-FLAG proteins. Solid black box indicates a FLAG epitope. $\boldsymbol{E}$, The expression pattern of Reelin and density of Cajal-Retzius cells in MZ were not affected in $\Delta \mathrm{C}-\mathrm{KI}$ mice. Brain sections from the indicated mice at $\mathrm{P7}$ were immunostained with anti-Reelin antibody. Nuclei were stained with Hoechst 33342. Arrows indicate CajalRetzius cells in which accumulation of Reelin is observed. Scale bar, $200 \mu \mathrm{m}$. Quantification of the density of Cajal-Retzius cells in the MZ is shown at the right side of the panels. Error bars indicate mean \pm SEM $(n=3)$. $\boldsymbol{F}$, The amount of Reelin was increased in $\Delta C-K I$ mice. The homogenates of $\mathrm{P} 3$ mouse cerebral cortices from Reelin-deficient reeler mouse $(r / / r)$, wild-type $(+/+)$, or $\Delta C-K I(\Delta C / \Delta C)$ mice were analyzed by WB using the antibody indicated on the left of the panel. Asterisks indicate full-length Reelin. Arrowhead indicates the N-terminal fragment generated by $\mathrm{N}-\mathrm{t}$ cleavage (NR2). Molecular mass markers $(\mathrm{kDa}$ ) are shown on the right of the panels. Arrows indicate nonspecific bands. Quantification of the amount of full-length Reelin and NR2 is shown below the panels. Error bars indicate mean \pm SEM. ${ }^{*} p<0.05$ (one-sample $t$ test). N.S., Not significant. $n=4$. G, The amount of Reelin secretion was approximately equivalent in wild-type and $\Delta C-K I$ mice. The supernatants and cell lysates from primary cultured cortical neurons of wild-type $(+/+)$, or $\Delta C-K I(\Delta C / \Delta C)$ mice were analyzed by WB. Asterisk indicates full-length Reelin. Arrowhead indicates NR2. Quantification of the amount of full-length Reelin and NR2 is shown below the panels. Error bars indicate mean \pm SEM. ${ }^{*} p<$ 0.05 (one-sample $t$ test). N.S., not significant. $n=3$. $\boldsymbol{H}$, The amount of Dab1 was increased in $\Delta C$-KI mice. Homogenates of P3 mouse cerebral cortices were analyzed by WB. Anti- $\alpha$-tubulin was used as the loading control. Quantification of the amount of Dab1 is shown below the panels. Error bars indicate mean \pm SEM. $F_{(2,9)}=10.66 .{ }^{* *} p<0.01$ (Tukey's test). ${ }^{*} p<0.05$ (Tukey's test). N.S., Not significant. $n=4$.
}

\section{Reelin is proteolytically cleaved by proprotein convertases within its CTR}

During the course of studying the CTR, we observed that proteolytic cleavage might occur within the CTR in the following experiments. We expressed full-length Reelin with a FLAG-tag added to the CTR (ReelinC-FLAG), a Reelin mutant with a FLAG-tag inserted between RR8 and the CTR (ReelinFLAG + C), and a Reelin mutant without a CTR with a FLAG-tag on RR8 (Reelin $\Delta$ CFLAG) (Fig. 4A,B) in HEK293T cells. While each of the proteins was detected in the culture supernatant by the antibody against RR8 (Fig. 4C, lanes 1-3), only ReelinFLAG $+\mathrm{C}$ and Reelin $\Delta \mathrm{C}$ FLAG were detected using the anti-FLAG antibody (Fig. 4C, lanes 5 and 6). ReelinC-FLAG in the cell lysate was recognized by the anti-FLAG antibody (Fig. 4D, lane 4). These results suggest that proteolytic cleavage occurs within the CTR of Reelin; thus, the FLAG-tag is lost from the ReelinC-FLA. This is the third specific cleavage site reported for Reelin and is henceforth called the WC (i.e., within the CTR) site.

The Reelin CTR contains a consensus sequence for the PC family of proteases (Thomas, 2002) (boxed in Fig. 4A). When ReelinC-FLAG was expressed in HEK293T or COS-7 cells in the presence of decanoyl-RVKR-chloromethylketone (furin inhibitor-1, FI-1) or hexa-D-arginine (furin inhibitor-2, FI-2), secreted ReelinC-FLAG was detected using the anti-FLAG antibody (Fig. 4E, lanes 2, 3, 5, and 6), although the sensitivity to each inhibitor differs between the cell types. The necessity of PC family proteases in WC cleavage was further verified using a cell line (LoVo cells) (Takahashi et al., 1993) that bears no endogenous PC protease activity (Fig. $4 F$ ). These results indicate that PC family proteases cleave Reelin at the WC site. To examine whether WC cleavage occurs at a consensus sequence within the CTR, we prepared an AP-fusion protein of RR7, RR8, and the CTR of Reelin (RR78C) with a FLAG-tag on the CTR (AP-RR78CF), as well as two mutants in which single point mutations (R3455A or R3458A) were introduced (Fig. $4 G$ ). Each of the AP-fusion proteins was equally secreted into culture supernatants (Fig. $4 \mathrm{H}$, top), whereas only AP-RR78CF-R3455A was detected by the anti-FLAG antibody in the absence of FI-1 (Fig. 4H, bottom, lane 3 ), indicating that this mutant is resistant to cleavage by the PC family proteases. Together, these results indicate that WC cleavage occurs between R3455 and S3456 and liberates a peptide made up of the last 6 amino acids of Reelin.

To investigate whether WC cleavage occurs in endogenous Reelin, we established monoclonal antibodies that specifically recognize full-length Reelin with an intact CTR (ReelinFL). The antibodies we obtained, 12C10 and 1D4, recognized Reelin protein only when collected in the presence of FI-1 (Fig. 4I, lanes 2 and 4). They recognized neither Reelin protein that underwent WC cleavage (Fig. 4I, lanes 1 and 3 ) nor Reelin protein lacking the last 6 amino acids (Reelin $\Delta 6$; Fig. 4I, lanes 5 and 6). Reelin protein secreted from cerebellar granule neurons (CGNs) barely reacted with the 1D4 antibody (Fig. 4J, lane 3). When CGNs were cultured in the presence of FI-1, ReelinFL was clearly detected in their culture supernatant (Fig. 4J, lane 4). Therefore, most of the Reelin protein secreted by CGNs is cleaved at the WC site. FI-2, which does not inhibit all PC family members, blocked WC cleavage to a much lesser degree (Fig. $4 \mathrm{~J}$, lane 5), suggesting that a specific type of PC family protease catalyzes WC cleavage in CGNs. In the developing cerebral cortex, the ratio of ReelinFL was higher at embryonic day 15 (E15) than at P1 or P8 (Fig. 4K), suggesting that endogenous Reelin is also regulated by WC cleavage and that cleavage activity increases during late developmental stages. We found no difference between ReelinFL and Reelin $\Delta 6$ 

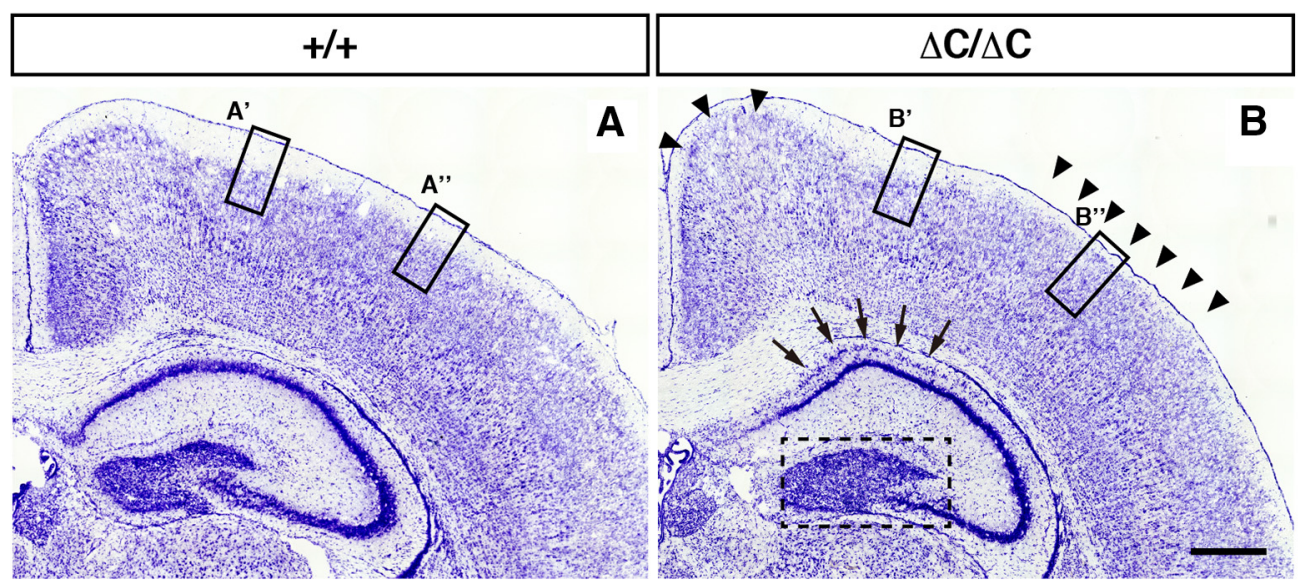

\begin{tabular}{|c|c|c|c|}
\hline$A^{\prime}$ & B' & $A^{\prime \prime}$ & B'” \\
\hline$+/+$ & $\Delta \mathrm{C} / \Delta \mathrm{C}$ & $+/+$ & $\Delta \mathrm{C} / \Delta \mathrm{C}$ \\
\hline
\end{tabular}
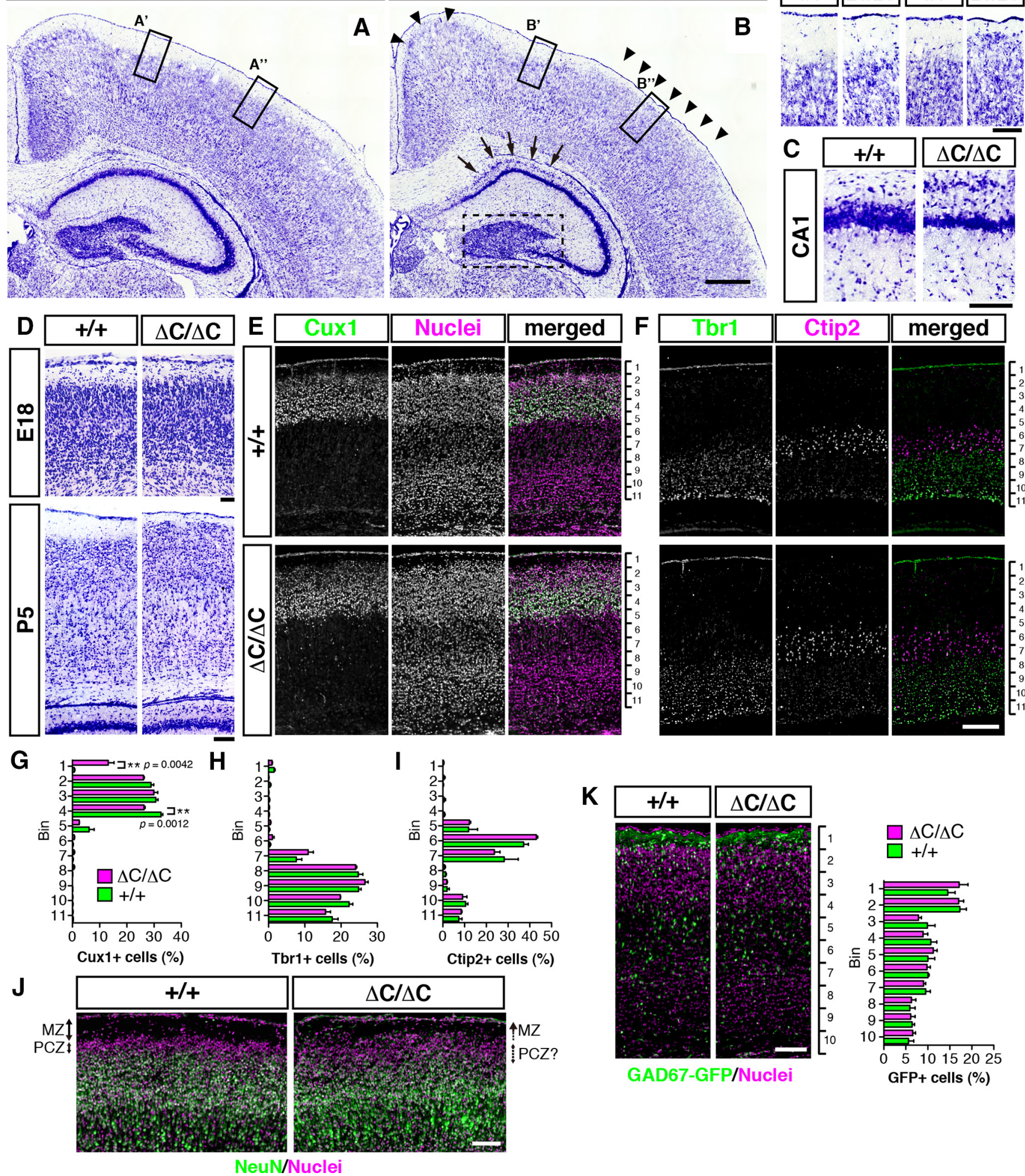

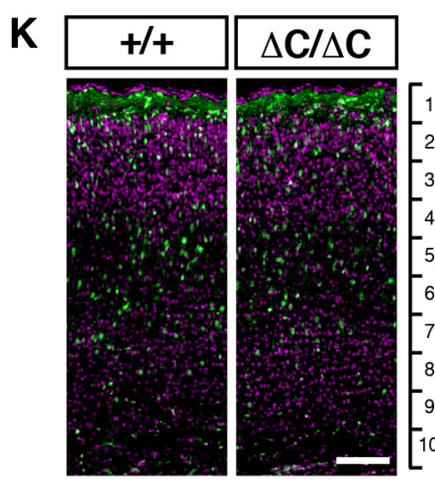

GAD67-GFP/Nuclei
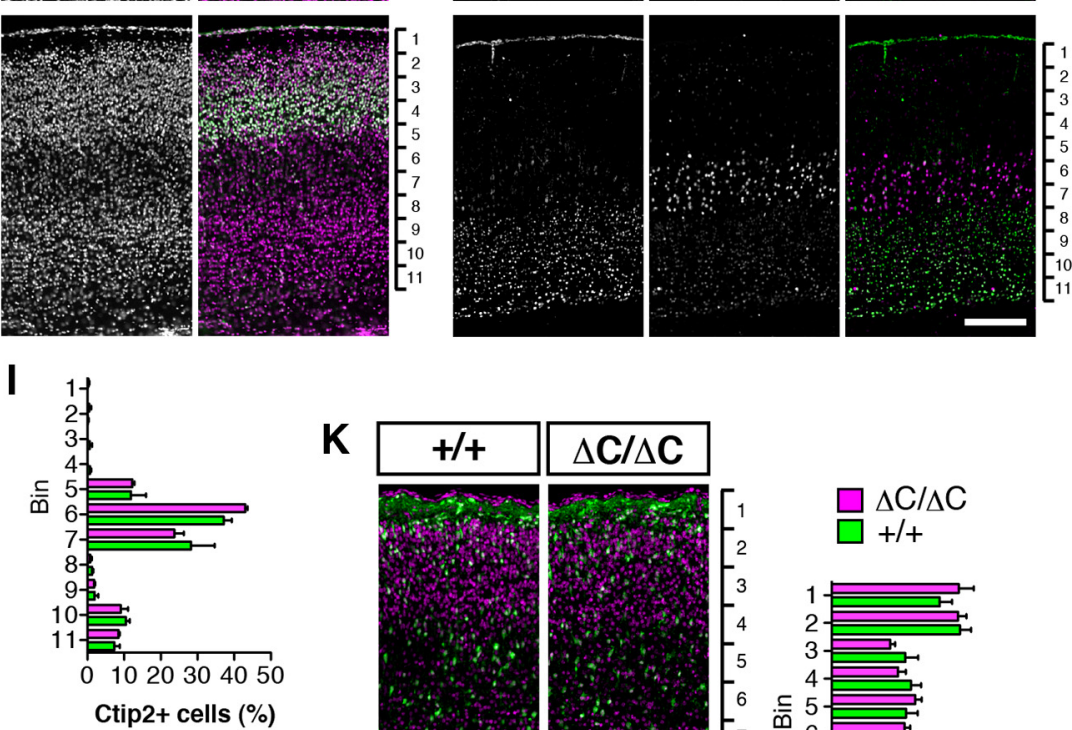

Figure 2. Formation of the $M Z$ and upper layers is abnormal in mice lacking the Reelin CTR. $A-C$, Nissl staining of sections of the wild-type $(+/+, A)$ and $\Delta C-K I(\Delta C / \Delta C, B)$ mice brain at $P 7$. In $\Delta \boldsymbol{C}-\mathrm{Kl}$ mice, the MZ was narrow ( $\boldsymbol{B}$, arrowheads), the $(\mathbf{A} 1$ pyramidal cell layer was split into two layers ( $\boldsymbol{B}$, arrows; $\boldsymbol{C}$, and the dentate granule cell layer ( $\boldsymbol{B}$, surrounded by broken line) was less packed compared with wild-type mice. Scale bars: $\boldsymbol{B}, 400 \mu \mathrm{m} ; \boldsymbol{B}^{\prime \prime}, \boldsymbol{C}, 100 \mu \mathrm{m}$. $\boldsymbol{D}$, The MZ is narrower in $\Delta C$-KI mice than in wild-type mice at P5, but not at E18. Scale bars: top, $50 \mu \mathrm{m} ;$ bottom, $100 \mu \mathrm{m}$. $\boldsymbol{E}, \boldsymbol{F}$, Brain sections from the indicated mice at P3 were immunostained with the indicated antibodies. Nuclei were stained with Hoechst 33342 ( $\boldsymbol{E}$, middle column). Scale bar, $200 \mu \mathrm{m}$. $\mathbf{G}-\boldsymbol{I}$, Quantification of the indicated layer markers demonstrates that $\mathrm{Cux}{ }^{+}{ }^{+}$cells are affected in $\Delta \mathrm{C}-\mathrm{KI}$ mice. Graphs represent the percentage of cells in each of the 11 equal-size vertical bins. Error bars indicate mean \pm SEM. ${ }^{* *} p<0.01$ (unpaired $t$ test). $n=3 . J$, Formation of PCZ is abnormal in $\Delta C$-KI mice. Brain sections from indicated mice at P2 were immunostained with anti-NeuN (green), and nuclei were stained with Hoechst 33342 (magenta). The MZ/PCZ border and PCZ/cortical plate border are clear in wild-type mice, and both are blurred in $\Delta C-K I$ mice. Scale bar, $100 \mu \mathrm{m}$. $\boldsymbol{K}$, The distribution of GAD67-GFP ${ }^{+}$interneurons was normal in $\Delta C$-KI mice. Brain sections from indicated mice bearing GAD67-GFP allele at $\mathrm{P} 3$ were immunostained with anti-GFP (green), and nuclei were stained with Hoechst 33342 (magenta). Scale bar, $100 \mu \mathrm{m}$. Graph represents the percentage of GFP ${ }^{+}$cells in each of the 10 equal-size vertical bins. Error bars indicate mean \pm SEM $(n=3)$. 


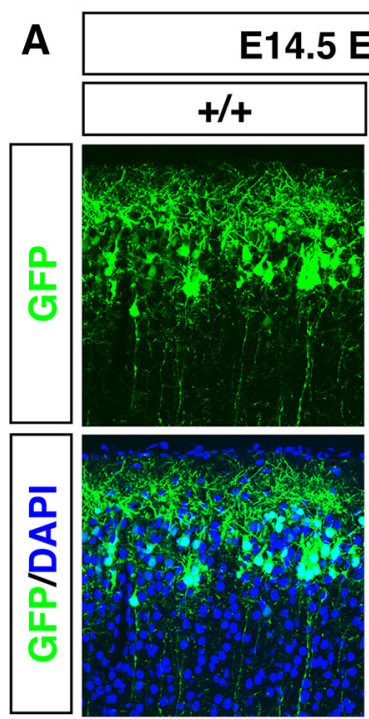

D

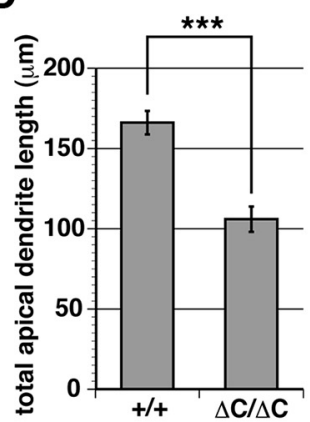

F

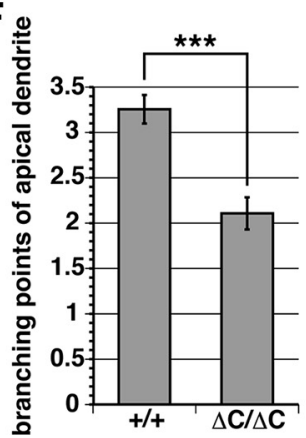

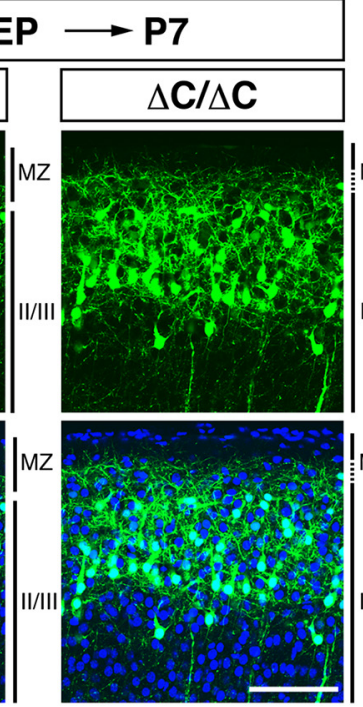

B

B
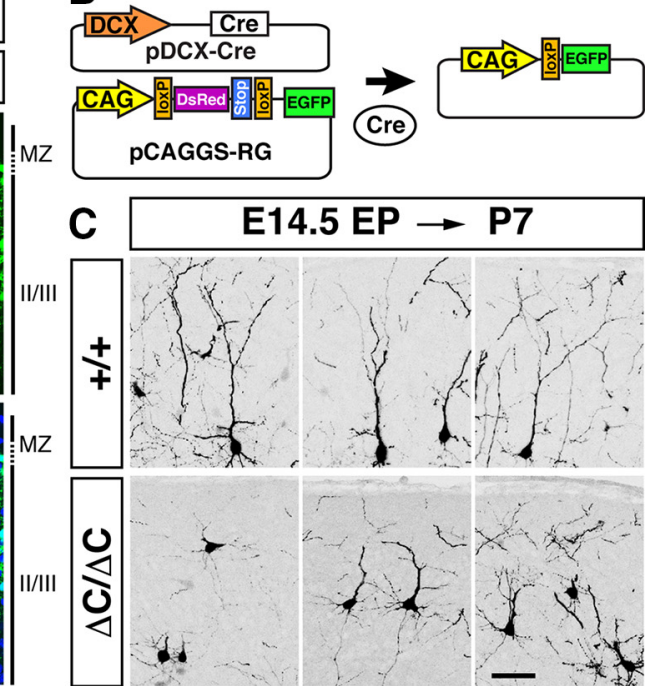

E

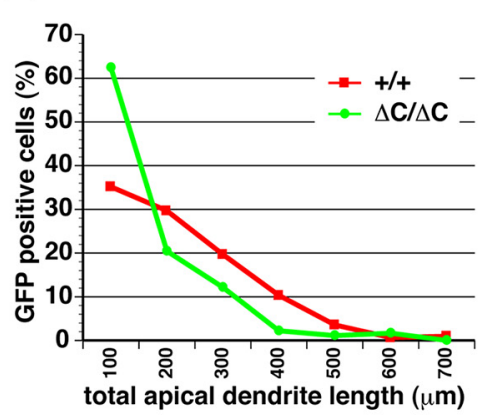

G

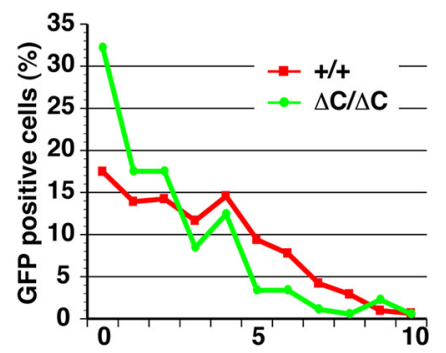

branching points of apical dendrite
$\mathbf{H}$

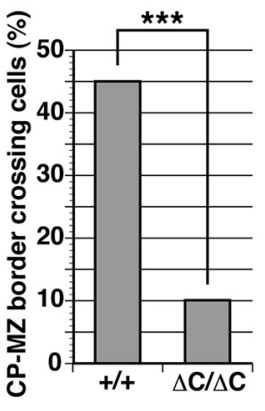

I Electroporated cells (\%)
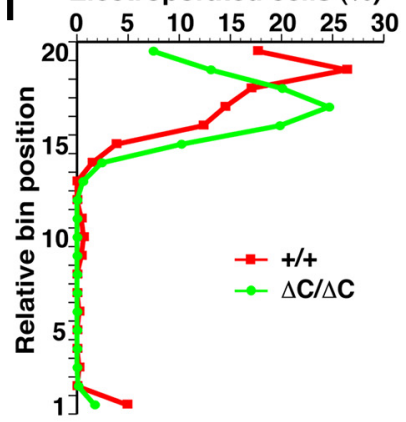

Figure 3. Development of apical dendrites is abnormal in mice lacking the Reelin CTR. $A$, In utero electroporation of GFP expression vectors was performed at E14.5, and mice were fixed at P7. The upper region of cerebral cortical slices is shown. II/III, Layer II/III. In $\Delta C-K I$ mice, the border between MZ and layer II/III is blurred. Scale bar, $100 \mu \mathrm{m}$. B, Schematic drawing represents the two plasmids used for sparse labeling of neurons ( $\mathrm{pDCX}$-Cre and pCAGGS-RG, left), and the plasmid resulting from (re-mediated recombination (right). In the absence of pDCX-Cre, $\mathrm{pCAGGS-RG} \mathrm{expresses}$ DsRed because of the presence of an SV40 polyadenylation sequence (Stop) after the DsRed, whereas in the presence of pDCX-Cre, Cre-mediated recombination excises the DsRed expression cassette and the Stop sequence through two loxP sites, and the resulting plasmid expresses GFP. To reduce the probability of recombination, the concentration of pDCX-Cre was reduced to one-fivehundredth compared with that of pCAGGS-RG, resulting in a small number of GFP-positive cells being observed. C, Sparse labeling by pCAGGS-RG/pDCX-Cre coelectroporation clearly shows the misorientation and hypertrophy of apical dendrites in $\Delta C-K I$ mice. Three representative images are shown. Scale bar, $50 \mu \mathrm{m}$. $\boldsymbol{D}$, Quantification of the total apical dendrite length $(p=3.729 \times$ $10^{-8},>30$ neurons from each of three different brains per group were analyzed). $E$, Line graph of the percentage of GFP ${ }^{+}$cells versus total apical dendrite length. $F$, Quantification of branching points of apical dendrites $\left(p=5.949 \times 10^{-7},>30\right.$ neurons from each of three different brains per group were analyzed). $G$, Line graph of the percentage of GFP ${ }^{+}$cells versus branching points of apical dendrites. $\boldsymbol{H}$, Quantification of the percentage of GFP ${ }^{+}$cells with apical dendrites that cross the border between the cortical plate and MZ $\left(p=5.307 \times 10^{-13},>50\right.$ neurons from each of three different brains per group were analyzed). $I$, Relative bin position of labeled neurons. Bin positions were calculated by measuring the distance from the ventricular surface to labeled cells and from the ventricular surface to the top of the cortical plate ( $>100$ neurons from each of three different brains per group were analyzed). $\boldsymbol{D}, \boldsymbol{F}, \boldsymbol{H}$, Error bars indicate mean \pm SEM. ${ }^{* * *} p<0.001$ (Mann-Whitney U test).

in the strength of induction of Dab1 phosphorylation in cultured primary cortical neurons (Fig. $4 L$ ). Immunohistochemical analysis using 12C10 antibody revealed that ReelinFL was present only in the direct vicinity of Cajal-Retzius cells in the MZ (Fig. $4 M$ ), raising the possibility that WC cleavage might play a role in regulating the localization or diffusion of Reelin protein.
RR78 with intact CTR binds to neuronal cell membrane

We next investigated whether the WC cleavage affects the interaction between Reelin and a molecule(s) expressed on the neuronal cell membrane. To exclude the effect of binding to canonical Reelin receptors, we used the AP-RR78C (Fig. 5A). Culturing in the presence of FI-I, AP-RR78C with an intact CTR 
A

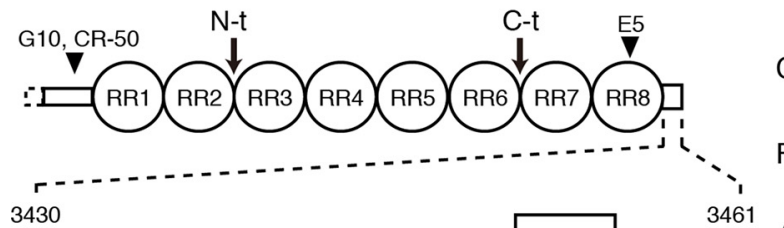

STRKQNYMMNFSRQHGLRHFYN RRRR SLRRYP* $\triangle \mathrm{C}-\mathrm{BLAG}$

D

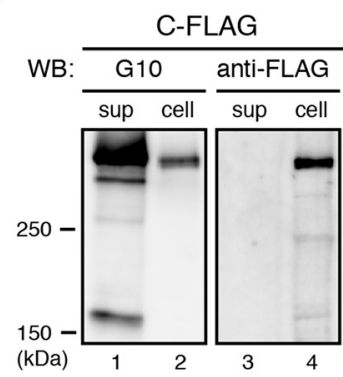

G

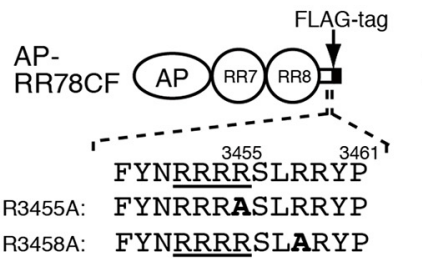

H AP- $\stackrel{\text { AP- }}{\text { RR78CF }} \stackrel{\text { AP- }}{\text { RR78CF }}$ RR78CF R3455A R3458A $\mathrm{Fl}-1-+\frac{\mathrm{R}}{-+} \frac{\mathrm{R}}{-+}$

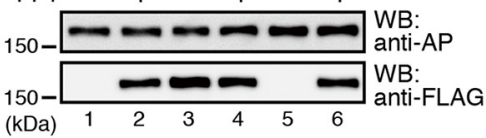

K

HEK293T: IP from brain w/ Fl-1 with CR-50

\begin{tabular}{ll:lll} 
WT & $\Delta 6$ & E15 & P1 & P8 \\
\hline stage
\end{tabular}

$\Longrightarrow$ WW:G10
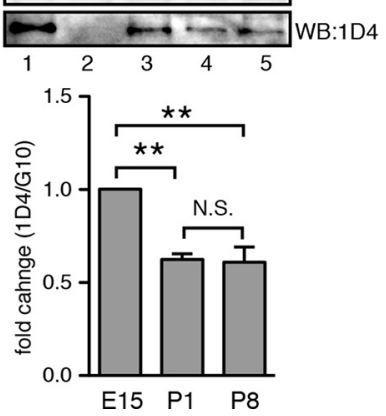

E $\quad \frac{\text { HEK293T }}{\text { C-FLAG }} \frac{\text { COS-7 }}{\text { AG }}$

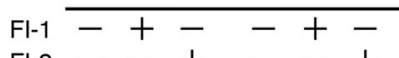

$\mathrm{FI}-2--+--+$

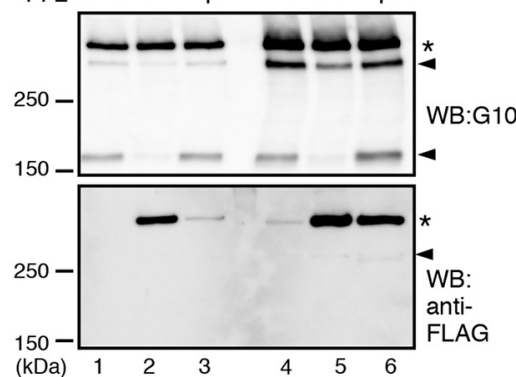

$\begin{array}{lllllll}(\mathrm{kDa}) & 1 & 2 & 3 & 4 & 5 & 6\end{array}$

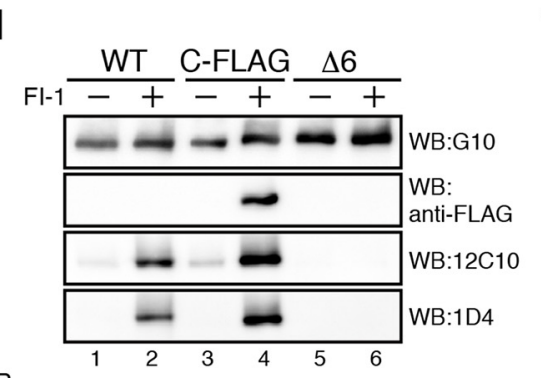

$\mathbf{L}$
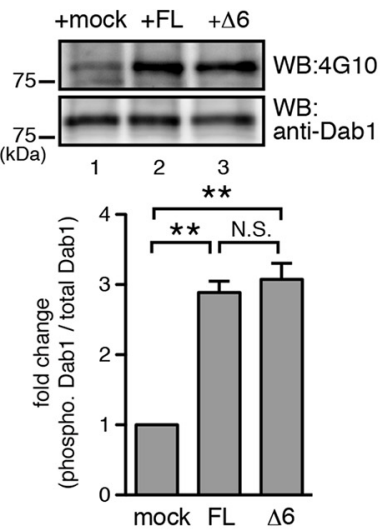

C WB:

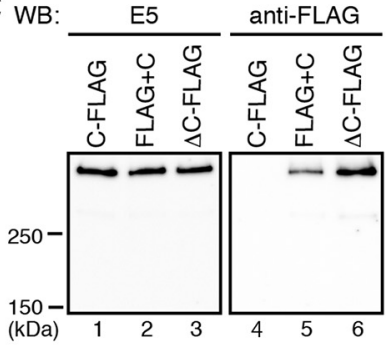

$\mathbf{F}$

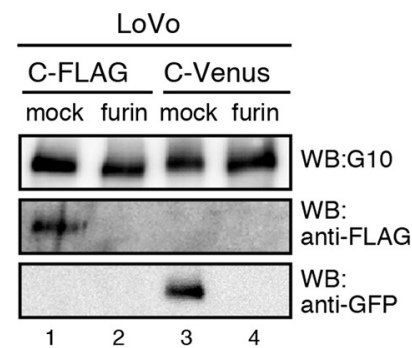

J

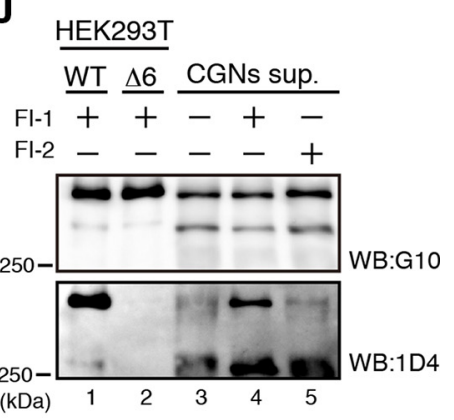

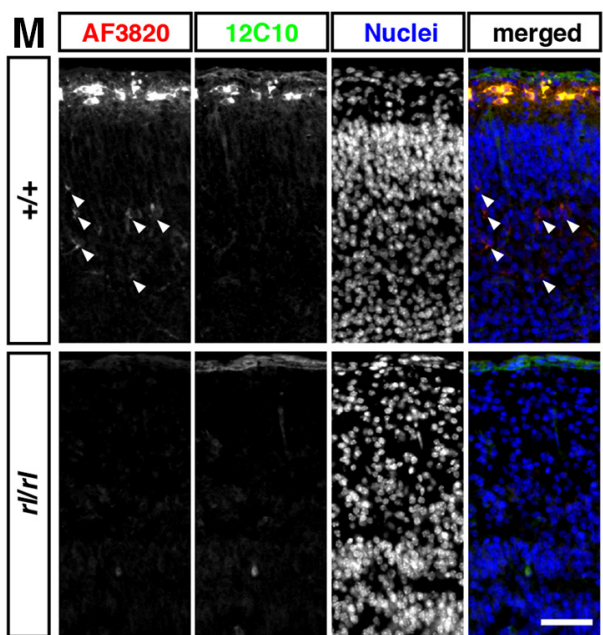

Figure 4. Reelin is cleaved within its CTR by PC family proteases. $A$, Schematic of Reelin protein and amino acid sequence of the CTR. Boxed region highlights the consensus sequence for PC family proteases. Arrows indicate two known cleavage sites. Arrowheads indicate epitopes of anti-Reelin antibodies. B, Schematic of Reelin mutants with a FLAG-tag. Solid black boxes represent FLAG-tags. C, Secreted ReelinC-FLAG did not retain its FLAG-tag. The culture supernatants of HEK293T cells expressing the above Reelin mutants were analyzed by WB with the indicated antibodies. The reactivity of ReelinFLAG + C to anti-FLAG antibody is weaker than Reelin $\Delta$ C-FLAG for unknown reason (Kohno et al., 2009b). D, Intracellular ReelinC-FLAG retained the FLAG-tag. The culture supernatants and whole-cell lysates of ReelinC-FLAG-expressing HEK293T cells were analyzed by WB. E, Reelin is cleaved by a PC family protease(s). The culture supernatants from ReelinC-FLAGexpressing HEK293T cells (lanes 1-3) or COS-7 cells (lanes 4 - 6) cultured without inhibitors (lanes 1 and 4), with Fl-1 (lanes 2 and 5), or Fl-2 (lanes 3 and 6) were analyzed by WB with G10 (top) or anti-FLAG (bottom). Asterisks indicate full-length Reelin. Arrowheads indicate Reelin fragments generated by cleavage within RR3 and cleavage between RR6 and RR7, respectively. Fl-1 inhibits cleavage at both sites (Kohno et al., 2009a). Secreted ReelinC-FLAG protein retained the FLAG-tag in the presence of the PC inhibitors (lanes 2, 3, 5, and 6). F, LoVo cells, which bear no endogenous PC activity, do not cleave Reelin at the WC site. The expression vector for ReelinC-FLAG or ReelinC-Venus was transfected into LoVo cells with or without a furin vector. The culture supernatant was collected and analyzed by WB with the indicated antibodies. G, Schematic of AP-RR78CF and its mutants. The consensus sequence of PC family proteases is underlined. (Figure legend continues.) 
was obtained (Fig. 5B). Primary cultured cerebral cortical neurons were incubated with control AP (SEAP; Fig. 5C, F, I), APRR78C collected in the absence of FI-1 (AP-RR78C- $\Delta 6$; Fig. $5 D, G, J$ ), or APRR78C collected in the presence of FI-1 (AP-RR78C-FL; Fig. 5E, $H, K$ ), followed by washes and detection using AP substrate. Only AP-RR78C-FL strongly bound to the neuronal cell membrane (Fig. 5E), which was inhibited by the 12C10 or 1D4 antibody (Fig. $5 \mathrm{H}$ and Fig. $5 K$, respectively). These results suggest the presence of a molecule(s) that binds only to the ReelinFL.

\section{Presence of an intact CTR is important for formation of the MZ-like structure driven by ectopic Reelin expression} Ectopic expression of Reelin by in utero electroporation leads to the formation of neuronal aggregates in vivo with a cellbody-sparse and dendrite-rich central area that resembles the $\mathrm{MZ}$ (Fig. 6A, left column) (Kubo et al., 2010). Reelin $\Delta$ CFLAG induced aggregation of neurons similar to full-length Reelin (ReelinCFLAG); however, the migrating neurons in the Reelin $\Delta$ C-FLAG-induced aggregates tended to invade the central MZ-like area (Fig. 6A, right column, $B)$. In particular, the same phenomenon was observed when Reelin $\Delta 6$ was expressed (Fig. $6 A$, middle column, $B$ ). In addition, aggregate cell density was highest with expression of ReelinCFLAG and was significantly lower when Reelin $\Delta 6$ or Reelin $\Delta$ CFLAG was expressed (Fig. 6C,D). Furthermore, ReelinC-FLAGexpressing neurons extended their leading processes to the center of the neuronal aggregates, whereas neurons expressing Reelin $\Delta 6$ or

\footnotetext{
(Figure legend continued.) Mutated amino acids are shown in bold. $\boldsymbol{H}, \mathrm{R} 3455$ is necessary for cleavage by PC family proteases. The culture supernatants of HEK293T cells expressing the indicated proteins with or without FI-1 were analyzed by WB. I, Monoclonal antibodies $12 \mathrm{C} 10$ and 1D4 specifically recognize ReelinFL. Wild-type Reelin (WT), ReelinC-FLAG, or a mutant Reelin lacking the last 6 residues $(\Delta 6)$ were expressed in HEK293T cells cultured with or without $\mathrm{Fl}-1$. The culture supernatants were analyzed by WB with the indicated antibodies. J, Fl-1 inhibits WC cleavage by CGNs. CGNs were cultured with the indicated inhibitors, and the culture supernatants were analyzed by WB. ReelinWT and Reelin $\Delta 6$ from HEK293T cells were run as references. $\boldsymbol{K}$, The ratio of endogenous Reelin protein cleaved at the WC site is dependent on developmental stage. Reelin proteins were immunoprecipitated using anti-Reelin CR-50 antibody from the brain homogenate at the indicated stages, analyzed by WB, and quantified. Error bars indicate mean \pm SEM. $F_{(2,6)}=19.42 .{ }^{* *} p<0.01$ (Tukey's test). N.S., Not significant. $n=$ 3. $L$, WC cleavage had little effect on the ability of Reelin to induce Dab1 phosphorylation in cultured cerebral cortical neurons in the standard assay. Cerebral cortical neurons were incubated for $20 \mathrm{~min}$ at $37^{\circ} \mathrm{C}$ with conditioned medium containing ReelinWT collected from HEK293T cells in the presence of Fl-1 (ReelinFL) or Reelin $\Delta 6$ collected in the presence of Fl-1. Whole-cell lysates were separated by SDS-PAGE followed by WB using anti-phosphotyrosine 4G10 (top) and anti-Dab1 (bottom) antibodies. Molecular mass markers ( $\mathrm{KDa}$ ) are shown on the left of the panel. Error bars indicate mean \pm SEM. $F_{(2,6)}=50.21 .{ }^{* *} p<0.01$ (Tukey's test). N.S., Not significant. $n=3 . \boldsymbol{M}$, ReelinFL localizes to the MZ. Sections of the cerebral cortices of wild-type $(+/+$, top) or reeler $(r / / r l$, bottom) mice at P1 were immunostained with AF3820 (antibody against the $\mathrm{N}$-terminal region of Reelin, red) and $12 \mathrm{C} 10$ (green). Nuclei were stained with Hoechst 33342 (blue). In sections from wild-type mice, the 12 C10 antibody stained CajalRetzius cells in the MZ. Arrowheads indicate signals positive for AF3820 only. Scale bar, $50 \mu \mathrm{m}$. $\boldsymbol{F}, \boldsymbol{I}, \boldsymbol{K}$, Only the bands of full-length Reelin protein $(430 \mathrm{kDa})$ are shown.
}

Reelin $\Delta$ C-FLAG had misoriented leading processes (Fig. 6E,F). Therefore, the presence of the last 6 amino acids of Reelin is required to prevent neuronal invasion into the central MZ-like area of aggregates, suggesting the possibility that ReelinFL is important for the development of the cell-body-sparse and dendrite-rich features of the MZ.

\section{Discussion}

Reelin is essential for the development of various regions of the nervous system (Tissir and Goffinet, 2003; Folsom and Fatemi, 2013) and plays important roles in the adult brain (Herz and Chen, 2006; Förster et al., 2010; Rogers et al., 2011). For one molecule to fulfill these versatile roles, multiple mechanisms must be involved in its spatiotemporal regulation. Here we report that the intact CTR of Reelin is necessary for the formation and maintenance of the MZ and dendrite development (Figs. 2 and 3 ). We also found that Reelin is subject to proteolytic cleavage by PC family proteases at a site proximal to the $\mathrm{C}$ terminus (Fig. 4). The function of this cleavage is likely to abrogate the interaction between Reelin and the neuronal cell membrane (Fig. 5). The presence of intact CTR is required for prevention of neuronal cell body invasion into the Reelin-concentrated area (Fig. 6). These findings provide novel conceptual and mechanistic insight for Reelin functions in neural development. Finally, we provide an in vivo demonstration that the CTR sequence is not essential for Reelin secretion and is replaceable with a FLAG sequence, which had first been suggested by Goffinet and colleagues (Lambert de Rouvroit et al., 1999) and subsequently detailed by ourselves (Nakano et al., 2007).

The large size of the mouse reelin gene, which spans $>450 \mathrm{kbp}$ and is composed of 65 exons, makes the creation of KI or conditional knock-out mice difficult. Fortunately, the CTR is encoded in a single exon, and we succeeded in generating a Reelin $\Delta \mathrm{C}-\mathrm{KI}$ mouse. Recently, Ha et al. (2015) performed a mutagenesis 
A
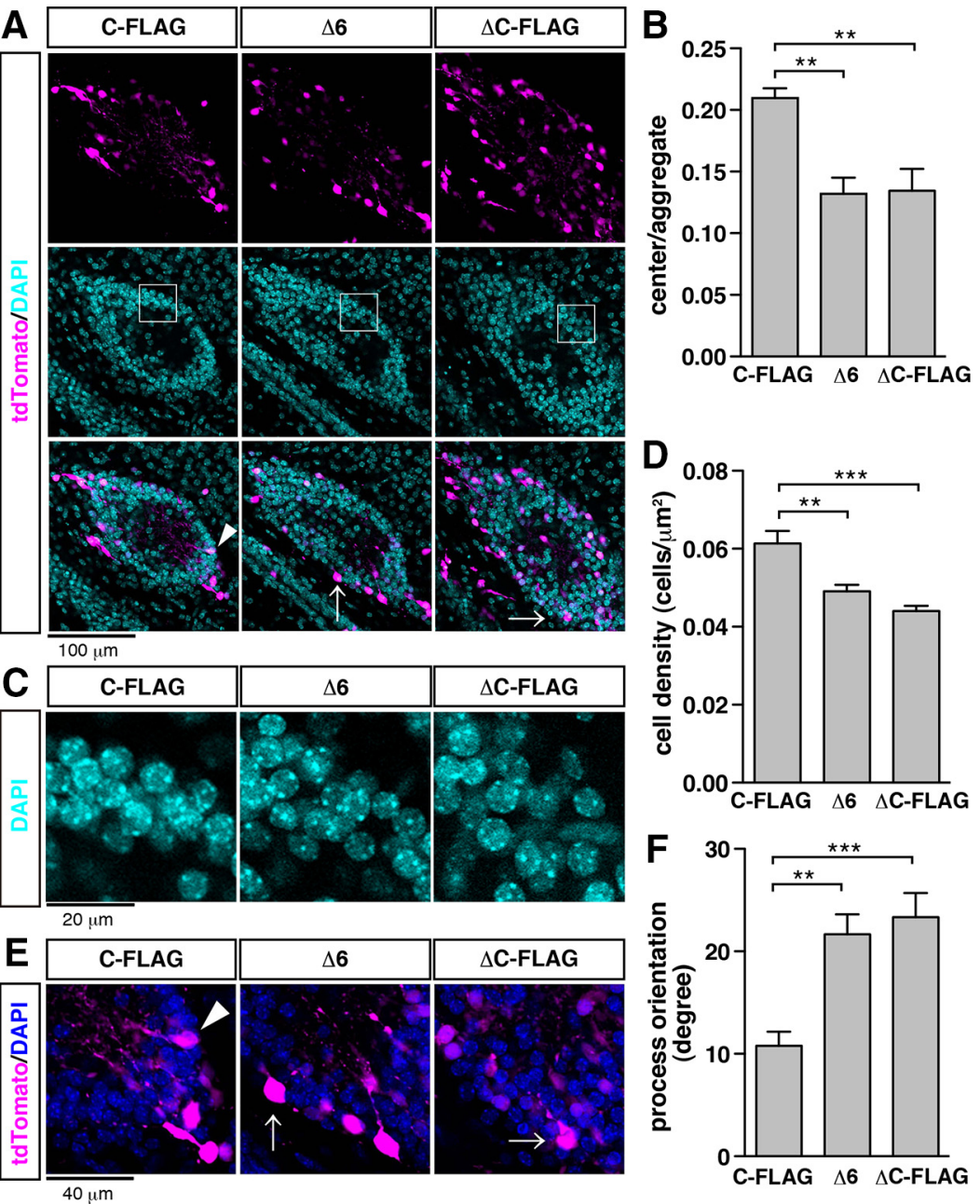

Figure 6. Reelin with an intact CTR is required for formation of the MZ structure. $A$, Neuronal aggregates induced by ectopic expression of Reelin. Mouse embryos were electroporated with the indicated vector and tdTomato vector (magenta) at E14.5 and fixed at P3. Nuclei were stained with DAPI (cyan). Scale bar, $100 \mu \mathrm{m}$. B, Quantification of relative areas of cell-body-sparse regions evaluated by the ratio of center to aggregate area $(n=7)$. C, Magnified images of the boxed areas in $\boldsymbol{A}$. Scale bar, $20 \mu \mathrm{m}$. $\boldsymbol{D}$, Quantification of cell density of neuronal aggregates $(n=7)$. $\boldsymbol{E}$, Magnified images of a neuronal aggregate in $\boldsymbol{A}$. Arrowhead and arrows indicate neurons that have processes oriented to the center of the neuronal aggregates and misoriented processes, respectively. Scale bar, $40 \mu \mathrm{m}$. $\boldsymbol{F}$, Quantification of neuronal process angles in neuronal aggregates $(n=7) . \boldsymbol{B}, \boldsymbol{D}, \boldsymbol{F}$, Error bars indicate mean \pm SEM. Tukey's test was used to test for statistical significance: $\boldsymbol{B}, F_{(2,18)}=10.73 ; \boldsymbol{D}, F_{(2,18)}=15.71 ; \boldsymbol{F}, F_{(2,201)}=10.30$. ${ }^{* * *} p<0.001 .{ }^{* *} p<0.01$.

screening study and obtained a mouse in which a mutation in the splicing site of the Reelin gene results in the appearance of unrelated amino acid sequence of five residues and a stop codon. In this mouse, the CTR of Reelin is totally absent and thus is presumed to be essentially equivalent to the model in the present study. Ha et al. (2015) reported that there are no gross abnormalities in the CNS of their mouse (Ha et al., 2015), although a detailed analysis was not performed. Interestingly, the amount of Reelin in the brain homogenate seemed to be increased in their mouse (Ha et al., 2015), which is consistent with our $\Delta \mathrm{C}-\mathrm{KI}$ mouse (Fig. $1 F$ ). It is thus suggested that neither the FLAG-tag in our mouse nor the abnormal sequence derived from aberrant splicing in their mouse affects the observed phenotypes, with the lack of the CTR solely accounting for the phenotype.

In the cerebral cortex of $\Delta \mathrm{C}$-KI mouse, the MZ becomes narrow after $\mathrm{P} 3$ because the upper-layer neurons invade the $\mathrm{MZ}$ and their apical dendrites are misoriented and poorly branched. The function of Reelin in cortical lamination can be classified into at least two classes. First, Reelin initiates or facilitates locomotion- type migration (Hack et al., 2007; Uchida et al., 2009; Simó et al., 2010; Jossin and Cooper, 2011; Pérez-Martínez et al., 2012). This process is mainly dependent on ApoER2 (Hack et al., 2007; PérezMartínez et al., 2012), which comprises the majority of the Reelin receptors in the developing cerebral cortex (Uchida et al., 2009). Second, Reelin operates in superficial positions (around the PCZ and MZ) to induce the transition to, and/or completion of, terminal translocation (Franco et al., 2011; Sekine et al., 2011; Chai et al., 2014). This process is dependent on VLDLR (Hack et al., 2007) and operates through the Dabl/integrin pathway (Sekine et al., 2012). The mRNA (Uchida et al., 2009) and protein (Hirota et al., 2015) expression patterns of VLDLR and ApoER2 also support these models. Here we found that the CTR-dependent pathway is only required for the latter event, and intact CTR is necessary for the Reelin binding to neuronal cell membrane (Fig. 5). It is thus possible that the specific interaction between ReelinFL and an unidentified receptor molecule ensures the events that only occur at the appropriate stages during brain development. In accordance with this model, MZ narrowing was also observed in Dab1 hypomorphic mice (Herrick and Cooper, 2004). One likely scenario would be that, near the MZ, ReelinFL binds to VLDLR as well as an unidentified coreceptor, which efficiently induces Dab1 phosphorylation. This "reinforced Dab1 signaling" leads to the correct orientation, growth, and branching of apical dendrites and, thus, maintenance of cell sparseness in the MZ. Cleavage at the WC site by PC family proteases may prohibit this specific pathway from operating in unwanted (i.e., deeper) regions. Another possibility is that ReelinFL specifically activates or induces a Dab1-independent pathway that plays an important role in the formation of the MZ. Identification of CTR-interacting molecules will be necessary to test this hypothesis.

From a biochemical point of view, the present findings provide two conceptually unique points. First, Reelin is one of the largest secreted signaling proteins with $>3400$ amino acid residues and its function is regulated by the presence or absence of a 6 amino acid peptide $(0.17 \%$ of whole polypeptide). Together with the fact that the primary sequence of CTR is $100 \%$ conserved in mammals (Nakano et al., 2007), this indicates that fine regulation of Reelin function in and around the CTR would be critically important for mammalian brains. Additionally, the difference in molecular weight between ReelinFL and Reelin $\Delta 6$ is too small to discern with SDS-PAGE. Therefore, it is not surprising that WC cleavage had not been discovered before this study. We presume that all recombinant Reelin proteins used in previous studies were likely Reelin $\Delta 6$, rather than ReelinFL, because almost all Reelin protein in supernatants of 
cultured cell lines was found to have undergone WC cleavage. This possibility should be considered in future studies using recombinant Reelin. Second, PC family proteases cleave Reelin at a site very close to the $\mathrm{C}$ terminus. As its name indicates, the PC family is well known for its role in the maturation of secreted proteins; and in most cases, it cleaves proteins at sites close to their $\mathrm{N}$ terminus (Thomas, 2002). However, a few previous studies have reported that the PC family proteases function in roles other than the conversion of proproteins (Adams et al., 1997; Liu et al., 2010). Therefore, the cleavage of extracellular signaling proteins by PC family proteases may be a rather general phenomenon.

In this study, we focused on the superficial structures of the cerebral cortex at early postnatal stages. Reelin plays important roles in many other systems at a variety of developmental stages. Furthermore, the $\Delta \mathrm{C}$-KI mouse is the first hypomorphic mutant of the reelin gene and could be used to investigate the role of Reelin in many systems. For example, it would be interesting to determine whether $\Delta \mathrm{C}$-KI mice have learning deficits because Reelin is involved in synapse formation and modulation of synaptic plasticity (Herz and Chen, 2006; Rogers et al., 2011). Finally, the observations, models, and tools presented in this study are also of clinical importance because reduced Reelin function has been suggested to be involved in the pathogenesis and/or deterioration observed in neuropsychiatric diseases (Folsom and Fatemi, 2013; Ishii et al., 2015). We anticipate that understanding how the versatile Reelin functions can be regulated will represent a significant advancement in our understanding of neuropsychiatric disorders.

\section{References}

Adams RH, Lohrum M, Klostermann A, Betz H, Püschel AW (1997) The chemorepulsive activity of secreted semaphorins is regulated by furindependent proteolytic processing. EMBO J 16:6077-6086. CrossRef Medline

Arnaud L, Ballif BA, Cooper JA (2003) Regulation of protein tyrosine kinase signaling by substrate degradation during brain development. Mol Cell Biol 23:9293-9302. CrossRef Medline

Chai X, Fan L, Shao H, Lu X, Zhang W, Li J, Wang J, Chen S, Frotscher M, Zhao S (2014) Reelin induces branching of neurons and radial glial cells during corticogenesis. Cereb Cortex pii: bhu216. CrossRef Medline

D’Arcangelo G, Miao GG, Chen SC, Soares HD, Morgan JI, Curran T (1995) A protein related to extracellular matrix proteins deleted in the mouse mutant reeler. Nature 374:719-723. CrossRef Medline

D'Arcangelo G, Nakajima K, Miyata T, Ogawa M, Mikoshiba K, Curran T (1997) Reelin is a secreted glycoprotein recognized by the CR-50 monoclonal antibody. J Neurosci 17:23-31. Medline

D'Arcangelo G, Homayouni R, Keshvara L, Rice DS, Sheldon M, Curran T (1999) Reelin is a ligand for lipoprotein receptors. Neuron 24:471-479. CrossRef Medline

de Bergeyck V, Nakajima K, Lambert de Rouvroit C, Naerhuyzen B, Goffinet AM, Miyata T, Ogawa M, Mikoshiba K (1997) A truncated Reelin protein is produced but not secreted in the 'Orleans' reeler mutation (Reln[rl-Orl]). Brain Res Mol Brain Res 50:85-90. CrossRef Medline

Flanagan JG, Cheng HJ, Feldheim DA, Hattori M, Lu Q, Vanderhaeghen P (2000) Alkaline phosphatase fusions of ligands or receptors as in situ probes for staining of cells, tissues, and embryos. Methods Enzymol 327: 19-35. CrossRef Medline

Folsom TD, Fatemi SH (2013) The involvement of Reelin in neurodevelopmental disorders. Neuropharmacology 68:122-135. CrossRef Medline

Förster E, Bock HH, Herz J, Chai X, Frotscher M, Zhao S (2010) Emerging topics in Reelin function. Eur J Neurosci 31:1511-1518. CrossRef Medline

Franco SJ, Martinez-Garay I, Gil-Sanz C, Harkins-Perry SR, Müller U (2011) Reelin regulates cadherin function via Dab1/Rap1 to control neuronal migration and lamination in the neocortex. Neuron 69:482-497. CrossRef Medline

Ha S, Stottmann RW, Furley AJ, Beier DR (2015) A forward genetic screen in mice identifies mutants with abnormal cortical patterning. Cereb Coretx 25:167-179. CrossRef Medline

Hack I, Hellwig S, Junghans D, Brunne B, Bock HH, Zhao S, Frotscher M (2007) Divergent roles of ApoER2 and Vldlr in the migration of cortical neurons. Development 134:3883-3891. CrossRef Medline

Herrick TM, Cooper JA (2004) High affinity binding of Dabl to Reelin receptors promotes normal positioning of upper layer cortical plate neurons. Brain Res Mol Brain Res 126:121-128. CrossRef Medline

Herz J, Chen Y (2006) Reelin, lipoprotein receptors and synaptic plasticity. Nat Rev Neurosci 7:850-859. CrossRef Medline

Hiesberger T, Trommsdorff M, Howell BW, Goffinet A, Mumby MC, Cooper JA, Herz J (1999) Direct binding of Reelin to VLDL receptor and ApoE receptor 2 induces tyrosine phosphorylation of disabled- 1 and modulates tau phosphorylation. Neuron 24:481-489. CrossRef Medline

Hirota Y, Kubo K, Katayama K, Honda T, Fujino T, Yamamoto TT, Nakajima K (2015) Reelin receptors ApoER2 and VLDLR are expressed in distinct spatiotemporal patterns in developing mouse cerebral cortex. J Comp Neurol 523:463-478. CrossRef Medline

Howell BW, Herrick TM, Cooper JA (1999) Reelin-induced tryosine phosphorylation of disabled 1 during neuronal positioning. Genes Dev 13: 643-648. CrossRef Medline

Howell BW, Herrick TM, Hildebrand JD, Zhang Y, Cooper JA (2000) Dab1 tyrosine phosphorylation sites relay positional signals during mouse brain development. Curr Biol 10:877-885. CrossRef Medline

Ichihara H, Jingami H, Toh H (2001) Three novel repetitive units of reelin. Brain Res Mol Brain Res 97:190-193. CrossRef Medline

Ishii K, Nagai T, Hirota Y, Noda M, Nabeshima T, Yamada K, Kubo KI, Nakajima K (2015) Reelin has a preventive effect on phencyclidineinduced cognitive and sensory-motor gating deficits. Neurosci Res pii: S0168-0103(14)00440-7. CrossRef Medline

Jossin Y, Cooper JA (2011) Reelin, Rap1 and N-cadherin orient the migration of multipolar neurons in the developing neocortex. Nat Neurosci 14:697-703. CrossRef Medline

Jossin Y, Ignatova N, Hiesberger T, Herz J, Lambert de Rouvroit C, Goffinet AM (2004) The central fragment of Reelin, generated by proteolytic processing in vivo, is critical to its function during cortical plate development. J Neurosci 24:514-521. CrossRef Medline

Kawauchi T, Chihama K, Nishimura YV, Nabeshima Y, Hoshino M (2005) MAP1B phosphorylation is differentially regulated by Cdk5/p35, Cdk5/ p25, and JNK. Biochem Biophys Res Commun 331:50-55. CrossRef Medline

Kohno S, Kohno T, Nakano Y, Suzuki K, Ishii M, Tagami H, Baba A, Hattori M (2009a) Mechanism and significance of specific proteolytic cleavage of Reelin. Biochem Biophys Res Commun 380:93-97. CrossRef Medline

Kohno T, Nakano Y, Kitoh N, Yagi H, Kato K, Baba A, Hattori M (2009b) C-terminal region-dependent change of antibody-binding to the Eighth Reelin repeat reflects the signaling activity of Reelin. J Neurosci Res 87: 3043-3053. CrossRef Medline

Koie M, Okumura K, Hisanaga A, Kamei T, Sasaki K, Deng M, Baba A, Kohno T, Hattori M (2014) Cleavage Reelin repeat 3 regulates the duration and range of the signaling activity of Reelin protein. J Biol Chem 289:1292212930. CrossRef Medline

Koresawa Y, Miyagawa S, Ikawa M, Matsunami K, Yamada M, Okabe M, Shirakura R (2000) A new Cre recombinase gene based on optimal codon usage in mammals: a powerful material for organ-specific gene targeting. Transplant Proc 32:2516-2517. CrossRef Medline

Kubo K, Honda T, Tomita K, Sekine K, Ishii K, Uto A, Kobayashi K, Tabata H, Nakajima K (2010) Ectopic Reelin induces neuronal aggregation with a normal birthdate-dependent "inside-out" alignment in the developing neocortex. J Neurosci 30:10953-10966. CrossRef Medline

Lambert de Rouvroit C, Bernier B, Royaux I, de Bergeyck V, Goffinet AM (1999) Evolutionally conserved, alternative splicing of reelin during development. Exp Neurol 156:229-238. CrossRef Medline

Liu J, Afroza H, Rader DJ, Jin W (2010) Angiopoietin-like protein 3 inhibits lipoprotein lipase activity through enhancing its cleavage by proprotein convertases. J Biol Chem 285:27561-27570. CrossRef Medline

Nakano Y, Kohno T, Hibi T, Kohno S, Baba A, Mikoshiba K, Nakajima K, Hattori M (2007) The extremely conserved C-terminal region of Reelin is not necessary for secretion but is required for efficient activation of downstream signaling. J Biol Chem 282:20544-20552. CrossRef Medline Niwa H, Yamamura K, Miyazaki J (1991) Efficient selection for high- 
expression transfectants with a novel eukaryotic vector. Gene 108:193199. CrossRef Medline

Ogawa M, Miyata T, Nakajima K, Yagyu K, Seike M, Ikenaka K, Yamamoto H, Mikoshiba K (1995) The reeler gene-associated antigen on Cajal-Retzius neurons is a crucial molecule for laminar organization of cortical neurons. Neuron 14:899-912. CrossRef Medline

Pérez-Martínez FJ, Luque-Rio A, Sakakibara A, Hattori M, Miyata T, Luque JM (2012) Reelin-dependent ApoER2 downregulation uncouples newborn neurons from progenitor cells. Biol Open 1:1258-1263. CrossRef Medline

Rice DS, Sheldon M, D'Arcangelo G, Nakajima K, Goldowitz D, Curran T (1998) Disabled-1 acts downstream of Reelin in a signaling pathway that controls laminar organization in the mammalian brain. Development 125:3719-3729. Medline

Rogers JT, Rusiana I, Trotter J, Zhao L, Donaldson E, Pak DT, Babus LW, Peters M, Banko JL, Chavis P, Rebeck GW, Hoe HS, Weeber EJ (2011) Reelin supplementation enhances cognitive ability, synaptic plasticity, and dendritic spine density. Learn Mem 18:558-564. CrossRef Medline

Sado Y, Inoue S, Tomono Y, Omori H (2006) Lymphocytes from enlarged iliac lymph nodes as fusion partners for the production of monoclonal antibodies after a single tail base immunization attempt. Acta Histochem Cytochem 39:89-94. CrossRef Medline

Sakaguchi N, Kimura T, Matsushita S, Fujimura S, Shibata J, Araki M, Sakamoto T, Minoda C, Kuwahara K (2005) Generation of high-affinity antibody against $\mathrm{T}$ cell-dependent antigen in the Ganp gene-transgenic mouse. J Immunol 174:4485-4494. CrossRef Medline

Sekine K, Honda T, Kawauchi T, Kubo K, Nakajima K (2011) The outermost region of the developing cortical plate is crucial for both the switch of the radial migration mode and the Dab1-dependent "inside-out" lamination in the neocortex. J Neurosci 31:9426-9439. CrossRef Medline

Sekine K, Kawauchi T, Kubo K, Honda T, Herz J, Hattori M, Kinashi T, Nakajima K (2012) Reelin controls neuronal positioning by promoting cell-matrix adhesion via inside-out activation of integrin alpha5betal. Neuron 76:353-369. CrossRef Medline

Simó S, Jossin Y, Cooper JA (2010) Cullin 5 regulates cortical layering by modulating the speed and duration of Dab1-dependent neuronal migration. J Neurosci 30:5668-5676. CrossRef Medline

Tabata H, Nakajima K (2001) Efficient in utero gene transfer system to the developing mouse brain using electroporation: visualization of neuronal migration in the developing cortex. Neuroscience 103:865-872. CrossRef Medline

Takahashi S, Kasai K, Hatsuzawa K, Kitamura N, Misumi Y, Ikehara Y, Murakami K, Nakayama K (1993) A mutation of furin causes the lack of precursor-processing activity in human colon carcinoma LoVo cells. Biochem Biophys Res Commun 195:1019-1026. CrossRef Medline

Tamamaki N, Yanagawa Y, Tomioka R, Miyazaki J, Obata K, Kaneko T (2003) Green fluorescent protein expression and colocalization with calretinin, parvalbumin, and somatostatin in the GAD67-GFP knock-in mouse. J Comp Neurol 467:60-79. CrossRef Medline

Thomas G (2002) Furin at the cutting edge: from protein traffic to embryogenesis and disease. Nat Rev Mol Cell Biol 3:753-766. CrossRef Medline

Tissir F, Goffinet AM (2003) Reelin and brain development. Nat Rev Neurosci 4:496-505. CrossRef Medline

Trommsdorff M, Gotthardt M, Hiesberger T, Shelton J, Stockinger W, Nimpf J, Hammer RE, Richardson JA, Herz J (1999) Reeler/Disabled-like disruption of neuronal migration in knock-out mice lacking the VLDL receptor and ApoE receptor 2. Cell 97:689-701. CrossRef Medline

Trotter JH, Lussier AL, Psilos KE, Mahoney HL, Sponaugle AE, Hoe HS, Rebeck GW, Weeber EJ (2014) Extracellular proteolysis of reelin by tissue plasminogen activator following synaptic potentiation. Neuroscience 274:299-307. CrossRef Medline

Uchida T, Baba A, Pérez-Martínez FJ, Hibi T, Miyata T, Luque JM, Nakajima K, Hattori M (2009) Downregulation of functional Reelin receptors in projection neurons implies that primary Reelin action occurs at early/ premigratory stages. J Neurosci 29:10653-10662. CrossRef Medline

Verbrugghe P, Bouwer S, Wiltshire S, Carter K, Chandler D, Cooper M, Morar B, Razif MF, Henders A, Badcock JC, Dragovic M, Carr V, Almeida OP, Flicker L, Montgomery G, Jablensky A, Kalaydjieva L (2012) Impact of the Reelin signaling cascade (ligands-receptors-adaptor complex) on cognition in schizophrenia. Am J Med Genet B Neuropsychiatr Genet 159B:392-404. CrossRef Medline

Wang X, Qiu R, Tsark W, Lu Q (2007) Rapid promoter analysis in developing mouse brain and genetic labeling of young neurons by doublecortinDsRed-express. J Neurosci Res 85:3567-3573. CrossRef Medline

Yasui N, Nogi T, Kitao T, Nakano Y, Hattori M, Takagi J (2007) Structure of a receptor-binding fragment of reelin and mutational analysis reveal a recognition mechanism similar to endocytic receptors. Proc Natl Acad Sci U S A 104:9988-9993. CrossRef Medline 